University of Rhode Island

DigitalCommons@URI

Open Access Master's Theses

2020

\title{
ASSESSING THE IMPACT OF AN ARTIFICIAL REEF TO MITIGATE COASTAL EROSION USING THE PHASE RESOLVING WAVE MODEL FUNWAVE
}

Michael Gardner

University of Rhode Island, mikeg11940@gmail.com

Follow this and additional works at: https://digitalcommons.uri.edu/theses

\section{Recommended Citation}

Gardner, Michael, "ASSESSING THE IMPACT OF AN ARTIFICIAL REEF TO MITIGATE COASTAL EROSION USING THE PHASE RESOLVING WAVE MODEL FUNWAVE" (2020). Open Access Master's Theses. Paper 1904.

https://digitalcommons.uri.edu/theses/1904

This Thesis is brought to you for free and open access by DigitalCommons@URI. It has been accepted for inclusion in Open Access Master's Theses by an authorized administrator of DigitalCommons@URI. For more information, please contact digitalcommons-group@uri.edu. 
ASSESSING THE IMPACT OF AN ARTIFICIAL REEF TO MITIGATE COASTAL

EROSION USING THE PHASE RESOLVING WAVE MODEL FUNWAVE

BY

MICHAEL GARDNER

A THESIS SUBMITTED IN PARTIAL FULFILLMENT OF THE

REQUIREMENTS FOR THE DEGREE OF

MASTER OF SCIENCE

IN

OCEAN ENGINEERING

UNIVERSITY OF RHODE ISLAND

2020 


\section{MASTER OF SCIENCE IN OCEAN ENGINEERING}

OF

\section{MICHAEL GARDNER}

\section{APPROVED:}

Thesis Committee:

$\begin{array}{ll}\text { Major Professor } & \text { Annette Grilli } \\ \text { Aaron Bradshaw } & \text { Christopher Baxter } \\ & \text { Stephan Grilli } \\ & \text { Nasser H. Zawia } \\ & \text { DEAN OF THE GRADUATE SCHOOL }\end{array}$

UNIVERSITY OF RHODE ISLAND

2020 


\begin{abstract}
A Fully Non-Linear Boussinesq wave phase resolving model (FUNWAVE) (Shi et al., 2012) is used to model extreme storm events and assess their impact on the shoreline. In addition, we explore the potential benefit of deploying an artificial reef to mitigate the erosion on the shoreline. Individual waves are modeled in the time domain including all of the physical processes associated with their propagation: breaking, refraction, diffraction, reflection and non-linear effects. The study site modeled in these simulations is located in South Kingstown, Rhode Island, including the Green Hill Beach area along the coast. A sensitivity study on the FUNWAVE Courant-FriedrichsLewy (CFL) input parameter is completed and a value of 0.15 is determined to best generate the intended wave spectrum for our simulated cases. Results compare identical simulations run in FUNWAVE for cases with and without a submerged reef, deployed for coastal protection. This comparison shows that the implementation of a submerged reef along the coastline can significantly reduce both shoreward current velocities and wave energy. Resulting wave energy transmission coefficients moderately correlate with expected simplified solutions presented in Grilli et al. (1994) although the more realistic case evaluated in this study shows a greater reduction in wave energy across the reef. FUNWAVE's sediment transport module has proven to be difficult to use and has produced unreliable results for this study. The difference in coastal energy and current processes due to individual wave interaction with the seabed demonstrates the importance of utilizing a phase resolving model such as FUNWAVE to most accurately predict these conditions.
\end{abstract}




\section{ACKNOWLEDGMENTS}

I would first like to sincerely thank my major advisor, Dr. Annette Grilli, for her support and dedication throughout my graduate studies and providing insight into her vast knowledge of the coastal engineering field. I truly could not have persevered through the challenging moments during this process without her help.

I would also like to thank the other professors and students at the URI Ocean Engineering department that assisted me in my pursuit to complete this project and inspired me to put nothing but my best efforts into the questions we asked at the beginning of my thesis. MS Thesis candidates Janelle Skaden and Jennifer Brandes provided significant support in the understanding of XBeach and the model comparison effort.

A special thanks to Dr. Fengyan Shi at the University of Delaware for helping me to work through the numerous issues that arose as I learned and processed simulations in the FUNWAVE program. 


\section{PREFACE}

The following thesis has been prepared in completion of a Master's of Science in

Ocean Engineering under the title "Assessing the Impact of an Artificial Reef to Mitigate Coastal Erosion Using the Phase Resolving Wave Model FUNWAVE".

This work came about as the modeling pertains to my interests in coastal processes, shoreline protection and wave mechanics, and is a useful tool for understanding current issues relevant to the coastline in the state of Rhode Island. It is also timely, as there is presently a lot of interest in coastal flood mapping (and therefore modeling) in southern Rhode Island (Grilli et al., 2017a). Further, this study presented an opportunity to use the most recently updated version of the FUNWAVE model, which was released in 2019 and includes equations for sediment transport and coastal current effects.

This work strives to advance how we view the accuracy and capability of the coastal modeling process in preparation for storm events. Understanding morphological changes during these events can lead to improved and more effective coastal protection, storm warnings and flood zone mapping. Modeling such as that completed in this study can provide a more comprehensive understanding of coastal beach and property risk to storm events. Growing up along the coast and participating in many coastal activities, I value the protection of our shorelines and am passionate about how we can best mitigate coastal erosion issues. 


\section{TABLE OF CONTENTS}

PAGE

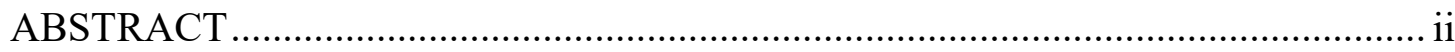

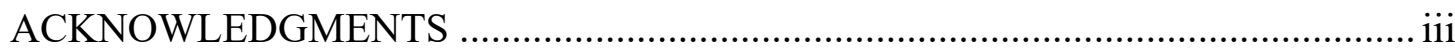

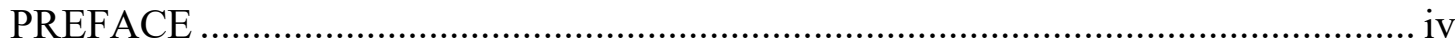

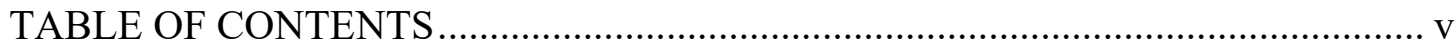

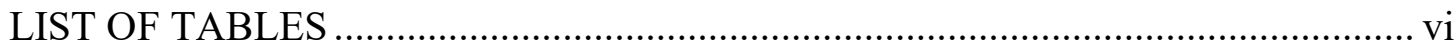

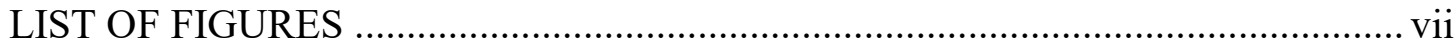

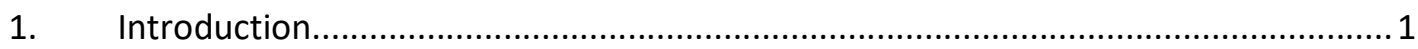

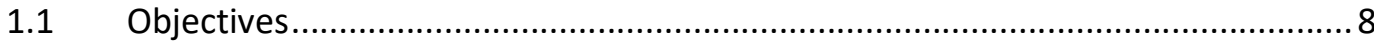

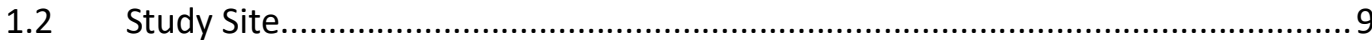

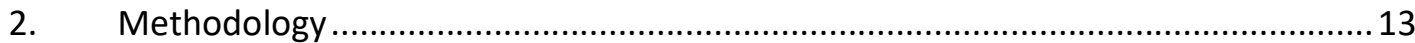

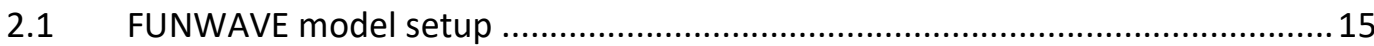

2.2 FUNWAVE calibration .............................................................................19

2.3 Simulation scenarios for unaltered conditions (no reef) .....................................22

2.4 Simulation scenarios with reef implementation.................................................25

2.5 Green Hill Study Site Simulation - Energy Transmission .....................................2 28

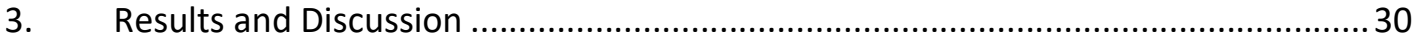

3.1 Transmission Coefficient Comparison ...............................................................

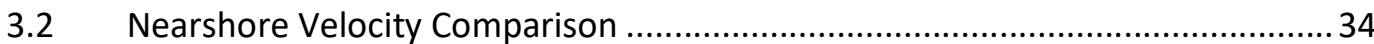

3.3 Power Density Spectrum Comparison ............................................................... 37

3.4 Sediment Transport Comparison ..................................................................... 39

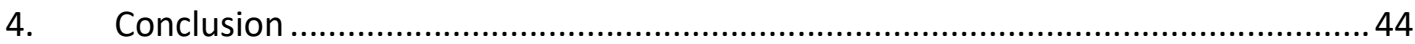

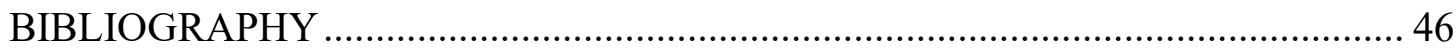




\section{LIST OF TABLES}

TABLE

PAGE

Table 1: FUNWAVE local computational grid ................................................. 10

Table 2: Hurricane Irene Initial Wave Maker Conditions ...................................... 17

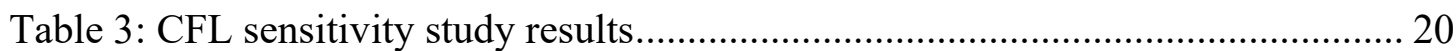

Table 4: Relative wave and energy transmission across the submerged reef area....... 30

Table 5: Total offshore to nearshore wave and energy transmission........................ 31

Table 6: Sediment change along transect directly inshore of the reef location in the study area. Values calculated between MSL (NAVD88) and the dune crest. ............. 39

Table 7: Sediment change along transect directly inshore of the reef location in the study area. Values calculated between 2 meters below MSL and the dune crest. ....... 39 


\section{LIST OF FIGURES}

FIGURE

PAGE

Figure 1: Location of the Green Hill Beach study area; the colormap shows the local bathymetry (vertical datum NAVD88); (a) Regional scale; (b) Local scale 11

Figure 2: Contour plot of the study area. Contours are placed every 1 meter from $-23 \mathrm{~m}$ depth offshore to the coastline (0 meters NAVD88). 12

Figure 3: Large, high energy surf at Green Hill Beach, RI......................................... 12

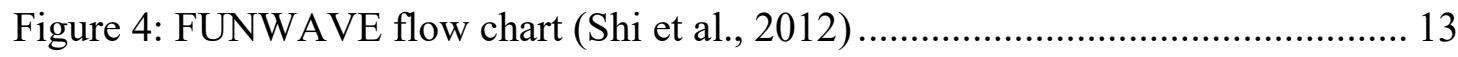

Figure 5: Example of image processing used to select structures from Google Earth. Purple marks are mostly representative of coastal homes. 16

Figure 6: The Torres et al., 2019 grid showing the nearest ADCIRC data point location in (green) to the center of the offshore boundary for the current study (red) 18

Figure 7: Significant wave height $(\mathrm{Hm} 0)$ and peak period $(\mathrm{Tp})$ taken at the location shown in Figure 6 from Torres et al. (2019) Hurricane Irene simulation results. 18

Figure 8: Study area showing the Hs (m) simulated during the sensitivity study of CFL for an input of $\mathrm{Hs}=4.42 \& \mathrm{CFL}=0.5$. Timestep shown is after $1400 \mathrm{~s}$ of wave propagation 21

Figure 9: Study area showing the Hs (m) simulated during the sensitivity study of CFL for an input of $\mathrm{Hs}=4.42 \& \mathrm{CFL}=0.15$. Timestep shown is after 3600s of wave propagation.

Figure 10: Unaltered (no reef) computational domain of the study area displaying the location of the virtual stations (Top); Zoomed in on the shoreline (Bottom); Colorbar shows the bathymetry/topography (m, MSL NAVD88). 24 
Figure 11: Manning friction coefficient over the study area (Schambach et al., 2018)25

Figure 12: Reef Altered study area displaying the location of simulated buoy stations

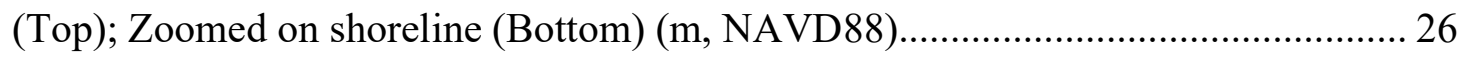

Figure 13: Input and smooth reef bathymetry comparison (Reef 1) ......................... 27

Figure 14: Input and smooth reef bathymetry comparison (Reef 2)......................... 27

Figure 15: Station locations for data collection. Data at each white dot was collected every 0.5 seconds during the simulation. Numbers represent stations used in transmission and energy calculations

Figure 16: Reef transmission coefficient values and the theoretical transmission coefficient location (red dot) on FIG 3 from (Grilli et al., 1994). Here, h' 1 is the reef height/ water depth and H' is wave height/ water depth. Values less than 1 on the $\mathrm{x}$ axis represent a submerged reef

Figure 17: Bathymetry color map overlaid with max current velocity vectors averaged over all time steps. Velocity vectors appear as lines with areas of stronger current represented by darker shaded areas; No reef (a); Reef 1 (b); Reef 2 (c) 35

Figure 18: Velocity difference between simulations (no reef case - reef case). Positive values indicate lower velocities after the reef was introduced. Reef 1 (top); Reef 2 (bottom) 36

Figure 19: Power Spectrum Density for Reef 1 (top) and Reef 2 (bottom) 200m offshore of the reef. The difference between the integral of the spectrum with and without a reef is representative of reflected energy 38

Figure 20: Erosion above MSL (NAVD88) in $\mathrm{m}^{3}$ after one hour of waves, FUNWAVE no reef (a), XBeach no reef (b) 40 
Figure 21: Erosion above MSL (NAVD88) in $\mathrm{m}^{3}$ after one hour of storm waves,

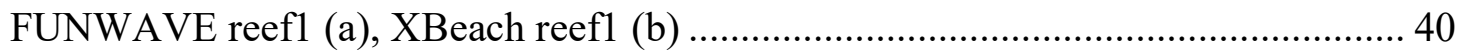

Figure 22: Nearshore erosion simulated using FUNWAVE after one hour of modeled time. No reef case (Top). Reef 1 case (Bottom). ...... 43 


\section{Introduction}

Erosion-related damage to coastal structures and property costs around $\$ 500$ million per year in the United States alone. Additionally, the federal government spends around $\$ 150$ million in beach nourishment and erosion mitigation strategies per year (NOAA, 2013). Worldwide, natural offshore reefs work as submerged barriers, dissipating wave energy offshore and reducing coastal wave impacts such as shoreline erosion. These reefs have proven to be very effective in the reduction of wave energy through breaking and friction across the reef. To create the best coastal protection scenarios, artificial reefs are best designed for each specific case with factors such as local bathymetry and wave climate playing the largest role in design. One study by (Harborne et al., 2006) shows that coral reefs reduce shoreward wave energy transmission by 95 percent. Grilli et al. (1994) modeled the energy transmission of solitary waves over both emerged and submerged breakwaters through both laboratory experiments and fully non-linear numerical computations. Results show that for a simplified solitary wave and trapezoidal breakwater case, submerged breakwaters can reduce wave energy transmission by 10 to $45 \%$. The study also found that the numerical computations overestimated the transmission by $2-7 \%$, most likely due to a lack of modeled energy dissipation. Through comparison of experiment observations, the potential flow calculations at the time could not account for the flow separation seen in these experiments, which lead to energy dissipation and wave amplitude reduction at the breakwater. 
Wave induced littoral currents, such as longshore and rip currents have a large effect on coastal erosion and sediment transportation. These currents are the result of shallow water waves and coastal bathymetry. Rip currents result from shallow water wave set-up and shoreward water transport returning offshore. Nearshore beach bathymetries with deep, narrow segments, where less wave breaking occurs, produce focused channels where water transported shoreward by waves can return offshore. It is well known that wider deep segments in nearshore bathymetry, in comparison to the shallower wave breaking area, result in slower return flow offshore (Kennedy et al., 2008). Kennedy et al., (2008) show how variations in sandbar length and spacing affect these nearshore currents. This study found that "the width of the offshore directed rip current increases only slowly with an increase in the width of the available rip channel", caused by the minimal variation in the shoreward water volume available to return offshore. Findings show how reef location and surrounding depth affect currents.

Using numerical models to simulate storm events and their impact on the shoreline, provides a rigorous quantification of the coastal hazard to the local communities and lends the necessary information to plan these mitigation strategies. Current coastal erosion and sediment transport models estimate the impact of storm events on coastal areas based on local sedimentology and wave climate. The existing state of the art erosion model, XBeach (Roelvink et al., 2009), is a fully coupled model using four interconnected modules: wave, flow, sediment transport and geomorphology. While the flow module includes the long infragravity waves in the time domain, the wave module includes only short waves in the spectral domain. This approach has the advantage of being computationally efficient but simplifies the short-wave representation and 
propagation. Short waves are assumed to be linear and while the refraction and breaking processes are included in their propagation, diffraction and reflection are not. While these simplifications are acceptable for general hazard assessment, they might not give realistic results when one desires to predict the flow in a built environment such as a coastal community with structures along the shoreline, or when one desires to study the effect of coastal or offshore structures to mitigate the storms, such as an artificial reef. Individual waves can also cause localized damage to structures along the coast and are therefore worth considering in modeling efforts (Park et al., 2018). Consequently, it is desirable to model individual waves propagating in the time domain including all of the physical processes associated with their propagation: breaking, refraction, diffraction, reflection and non-linear effects.

The wave model used in this study, the Fully Non-Linear Boussinesq wave phaseresolving model (FUNWAVE) (Shi et al., 2012) includes all of these processes. In addition, the model was recently extended to include an erosion module which contains a sediment transport and a geomorphological module updated in time, along with the propagation of individual waves. More specifically, a Boussinesq model contains equations applicable to waves with weak nonlinearity and weak frequency dispersion; however, the FUNWAVE model is fully nonlinear and fully dispersive, setting it apart from standard Boussinesq models. These wave attributes generally occur in shallow water, along the coast where refraction, diffraction, reflection and current interactions occur. Refraction occurs when ocean waves arrive in an intermediate and shallow water depth, waves begin to "feel" the bottom and slow-down in the shallower water. If bottom slopes are not even or the wave fronts approach at an angle, this causes the wave fronts 
to slow unevenly and bend towards the shallower water. Diffraction occurs when wave fronts approach an extremely steep obstacle, such as a breakwater or a harbor entrance, the wave front will change direction and bend towards the boundary, even if there is no change in water depth away from the boundary. Weak dispersion occurs as the dispersion relationship between waves becomes only a function of water depth in shallow water, causing all waves to travel at the same speed. In deep and intermediate water, waves with different wavelengths travel at different speeds, causing longer waves to propagate ahead of shorter waves. These equations are extremely important when modeling wave interactions in shallow water. Simplified, a phase-resolving model is a vertically integrated numerical solution that calculates individual surface waves as well as the velocity field using time-dependent momentum and mass equations. This model is free to the public on github.com. Access to any documentation for the program is also available online and was utilized for model setup, output assessment and troubleshooting purposes (Shi, 2020).

Southern Rhode Island is exposed to large storms and hurricanes which cause coastal erosion and damage to homes and businesses. Over the past five years the Rhode Island Shoreline Change Special Area Management Plan, known as Beach SAMP, produced a large amount of data and maps to assess the coastal risk in Rhode Island in terms of shoreline erosion and flooding (Beach SAMP, 2020; Spaulding et al., 2016; Spaulding et al., 2017). The methodology used to assess wave impacts and erosion along the shoreline has been constantly evolving to include increasingly complex processes. For example, while modeling beach and dune erosion used semi-empirical formulation for long term erosion, simple empirical assumptions were initially used for event scale 
erosion (Grilli et al., 2017a). Subsequently complex 2-D numerical modeling using the coupled morpho-hydrodynamic model XBeach (Roelvink et al., 2009) was used to assess the change of the shoreline during extreme events (Schambach et al., 2018); further work validated the methodology for specific erosion stages as defined by (Stockdon et al., 2007), confirming the ability of the model to accurately simulate erosion for varying vegetation coverage (Naser et al., 2018). Recently, the modeling team significantly improved the hydrodynamic portion of the wave module, modeling the wave propagation in real time using FUNWAVE, which includes non-linear and dynamics effects, such as wave runup (Grilli et al., 2020).

In parallel to the refinement of the numerical approach, several mitigation approaches have been explored such as beach nourishment and nature-based dune reinforcement (Naser et al., 2018). A current master's student, Jennifer Brandes, is focusing on optimizing the design and location of a potential artificial submerged breakwater as an erosion mitigation solution deployed along the southern shore of RI. The solution is inspired by current reef and living shoreline restoration projects (e.g., Reguero et al., 2018; Beck et al., 2018). Schambach et al., (2018), modeled the erosion along the southern coast of RI using the state-of the art geomorpho-dynamic model XBeach. The model was calibrated and validated with local measurements of beach volumes along Charlestown beach for Hurricane Irene (August, 2011) (Schambach et al., 2018). Hurricane Irene will similarly be used in this study to assess the validity of FUNWAVE's erosion module and the impact of an artificial reef on the local environment. 
The FUNWAVE Sediment Transport Module used in this study is part of the Boussinesq Model, incorporating sediment movement processes originating from the surf beat or infragravity waves, similar to other erosion models such as XBeach, as well as sediment transport initiated by the gravity wave propagation. Infragravity waves are low frequency surface gravity waves, who are normally defined in the frequency band between $0.04 \mathrm{~Hz}$ and $0.004 \mathrm{~Hz}$ ( 25 seconds to 4 minutes), as observed and described in many field studies such as (Elgar et al., 1993). These wavelengths correspond to the tail of the wave spectrum and are therefore much longer than most gravity waves produced by wind forcing; they have a significant importance shoreward of the surf zone, where short wave energy from swells and seas has dissipated due to wave breaking. Infragravity waves are created through nonlinear interactions and radiation stress forcing under two focal circumstances. The first type of infragravity wave is developed offshore. These waves are created by radiation stress forcing which causes sea level variations in conjunction with wave groups. These waves are constrained by the motions of the wave group and are therefore called bound waves. The second type of infragravity wave is developed at the surf-zone through radiation stress forcing caused by breaking. These waves are instantaneously free to propagate towards shore in the absence of the wave group due to short wave breaking (Longuet-Higgins, Michael S., and R. W. Stewart, 1964).

To calculate the movement of larger diameter sediment and that moving along the bottom, this module uses the bedload formulas identified by Meyer-Peter and Müller, (1948), as shown in the formulation bellow (Eq. 1), with, $q_{b}$, the transport rate of bed load in dry weight on unit channel width $\left(\mathrm{kg} \mathrm{s}^{-1} \mathrm{~m}^{-1}\right), \tau_{b}$, the flow shear stress acting 
on the channel bed, $\tau_{c r}^{b}$, the critical shear stress, $\rho_{w}$, the seawater density, $g$, the acceleration of gravity, and, s, the unit time step. For sediment suspension, the empirically derived pick-up function proposed in van Rijn, (1984), is utilized to calculate the suspended load and its transport to other areas of the seabed in the model. This function was determined through laboratory experiments and was compared to previously defined pick-up functions for both large $(>1,000 \mu \mathrm{m})$, and small $(<200 \mu \mathrm{m})$ particles.

$$
q_{b}=\frac{8\left[\left(\tau_{b}-\tau_{c r}^{b}\right) / \rho_{w]}^{3 / 2}\right.}{g(s-1)}
$$

The sediment module processes both cohesive (i.e. clay, silt and organic matter, frequently referred to as mud) and noncohesive sediment types (i.e. sand, gravel) in a similar fashion, utilizing the depth-averaged sediment concentration equation for advection and diffusion (Eq. 2).

$$
(\bar{c} H)_{t}+\nabla_{h} \cdot\left(\bar{c} H\left(u_{\alpha}+\bar{u}_{2}\right)\right)=\nabla_{h} \cdot\left(k H\left(\nabla_{h} \bar{c}\right)\right)+P-D
$$

In equation (2), $\mathrm{P}$ and $\mathrm{D}$ represent the erosion and deposition rate of sediment, respectively. The flow rate per unit width is represented by $H\left(u_{\alpha}+\bar{u}_{2}\right)$ (Shi et al., 2012), where $\mathrm{H}$ equals the total water depth, or the water depth, $\mathrm{h}+$ the free surface elevation, $\eta$. The $\bar{c}$ variable is the depth-averaged sediment concentration and is nondimensional and normalized by the provided density of the sediment. $\mathrm{K}$ is a coefficient representing horizontal sediment diffusion.

This thesis is structured as follows. Section 1 presents the introduction to concepts, objectives and the study site. In Section 2, the methodology used to produce the 
objective's results is explained. In the next section, the results of the study are presented, Section 3, followed by the study's conclusions, in Section 4.

\subsection{Objectives}

This study uses the fully non-linear, fully dispersive numerical wave model FUNWAVE coupled with its sediment module to simulate extreme storms along the southern Rhode Island shoreline. A comparison with previous modeling efforts using the state-of-the art model XBeach is performed and differences are discussed. In addition, FUNWAVE is used to simulate selected mitigation strategies along the shoreline, in particular a submerged offshore artificial reef.

Results of this study will be presented in terms of: (1) transmission coefficients, (2) subaerial eroded volumes along the shoreline and (3) accretion volumes between the reef and shoreline. Additionally, maps will be produced of wave propagation and coastal erosion for the simulated wave climates for both current conditions and for a bathymetry modified with the addition of an artificial reef. This work strives to provide an initial framework for an impact assessment of selected RI coastal areas modified with an artificial reef.

The study evaluates the implementation of an offshore reef for beach nourishment and protection, bringing to light nearshore hydrodynamic processes. In particular it demonstrates the concentration of wave energy on specific areas of the shoreline suggesting the possibility of mitigating the hazard, rather than only increasing the shoreline resilience. The implementation of an artificial reef theoretically reflects and dissipates part of the propagating wave energy, inducing lower current velocities and 
additional sediment deposition landward of the reef, consequently protecting the shoreline (Grilli et al., 1994). This reef effect has proven to be extremely efficient in natural reefs, resulting in an active field of research to restore damaged natural reefs (e.g., Reguero et al., 2018; Beck et al., 2018).

While the hydrodynamic module in FUNWAVE is fully calibrated and validated (Kirby et al., 2015) and therefore provides reliable wave elevation and velocity predictions, the erosion module is newly implemented and must be calibrated and validated at the study site. In this study, we aim to assess the accuracy of FUNWAVE when used with its sediment transport module, fully coupled with the hydrodynamic module, by comparing simulated erosion and measured erosion at the site for a selected historical storm (Irene, August 2011). Ultimately, we intend to assess the ability of a nature-based artificial reef deployed offshore of the study area to mitigate coastal erosion using FUNWAVE numerical simulations.

\subsection{Study Site}

The study area, Green Hill Beach (Figure 1), is situated on a stretch of coastline along southern Rhode Island consisting of a barrier beach system including dunes, beaches, lagoons and salt marshes, home to diverse vegetation and wildlife. The study area was chosen in a region where homes and fragile ecosystems border the coastline. This area also contains coastal lagoons, which can significantly manipulate the impact of extreme storms on the coastline and is of particular interest across southern RI.

The region is also being used as part of a continuous effort performed in ocean engineering at URI since 2015 to improve coastal and risk hazard assessment associated 
to extreme storms and changing climate in Rhode Island (Grilli et al., 2017b; Grilli et al., 2017a; Spaulding et al., 2016; Spaulding et al., 2017; Schambach et al., 2018; Naser et al., 2018). The Coastal Resource Management Council (CRMC) and a local association, the Friends of Greenhill Pond, have also supported the ocean engineering coastal team to evaluate the feasibility of storm hazard mitigation strategies on the RI shoreline.

The study site grid was chosen within the southern RI region of interest to best utilize the FUNWAVE model in the region, given the focus and constraints of the thesis (Table 1$)$. The long domain $(\sim 12 \mathrm{~km}$ in the offshore direction) was chosen to allow for the creation of long-waves in the model. The thin, $1 \mathrm{~km}$ width was chosen to be large enough for the implementation of a nearshore reef and to view nearshore processes but allow the model to be more computationally efficient. The Green Hill beach region is also a location along the coast of particular vulnerability to over-wash, as seen during historical storms, as well as damage to homes and property.

Table 1: FUNWAVE local computational grid

\begin{tabular}{|c|c|c|c|c|c|c|}
\hline Model & $\begin{array}{c}\text { Origin } \\
\text { (SE Corner) }\end{array}$ & $\begin{array}{c}\text { Site Size } \\
\mathbf{( k m )}\end{array}$ & $\begin{array}{c}\text { Cells } \\
\text { Cross- } \\
\text { shore }\end{array}$ & $\begin{array}{c}\text { Cells } \\
\text { Longshore }\end{array}$ & $\begin{array}{c}\text { Rotation } \\
\text { Angle }\end{array}$ & Friction \\
\hline FUNWAVE & $\begin{array}{l}41.271995, \\
-71.595100\end{array}$ & $1 \times 12.64$ & 6320 & 500 & $0^{\circ}$ & $\begin{array}{c}\text { Manning } \\
\text { (Variable) }\end{array}$ \\
\hline
\end{tabular}


(a)

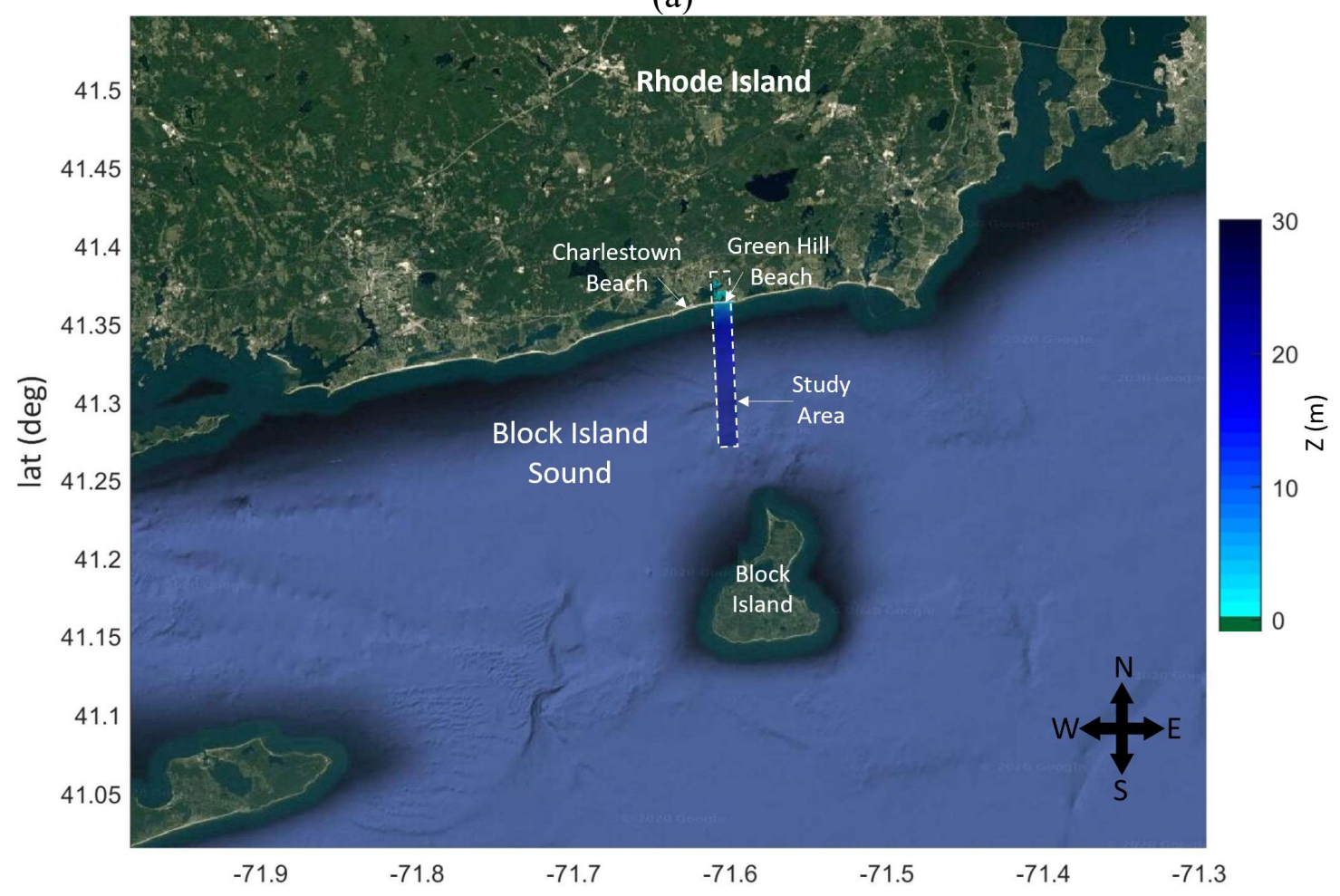

(b)

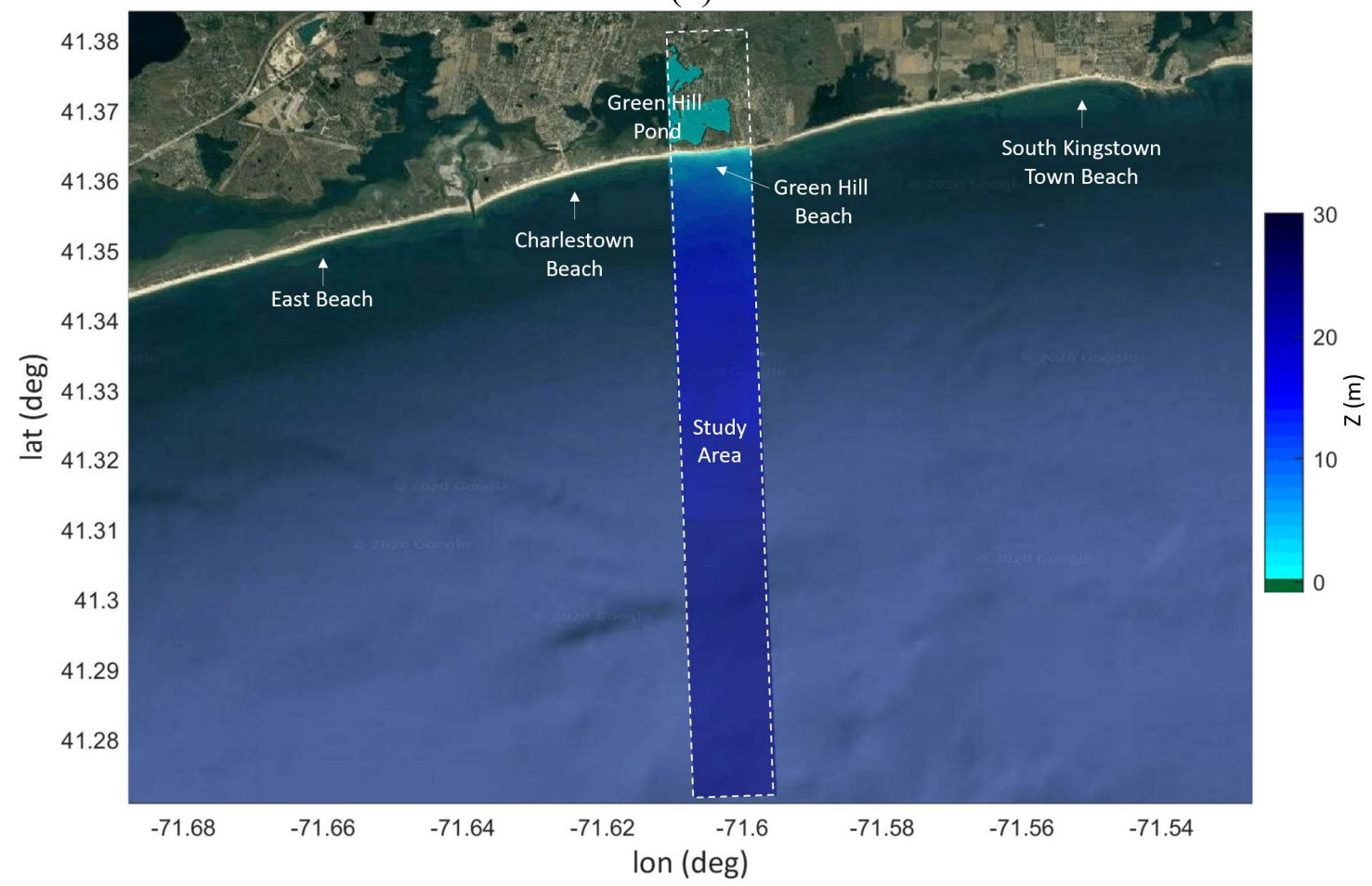

Figure 1: Location of the Green Hill Beach study area; the colormap shows the local bathymetry (vertical datum NAVD88); (a) Regional scale; (b) Local scale 


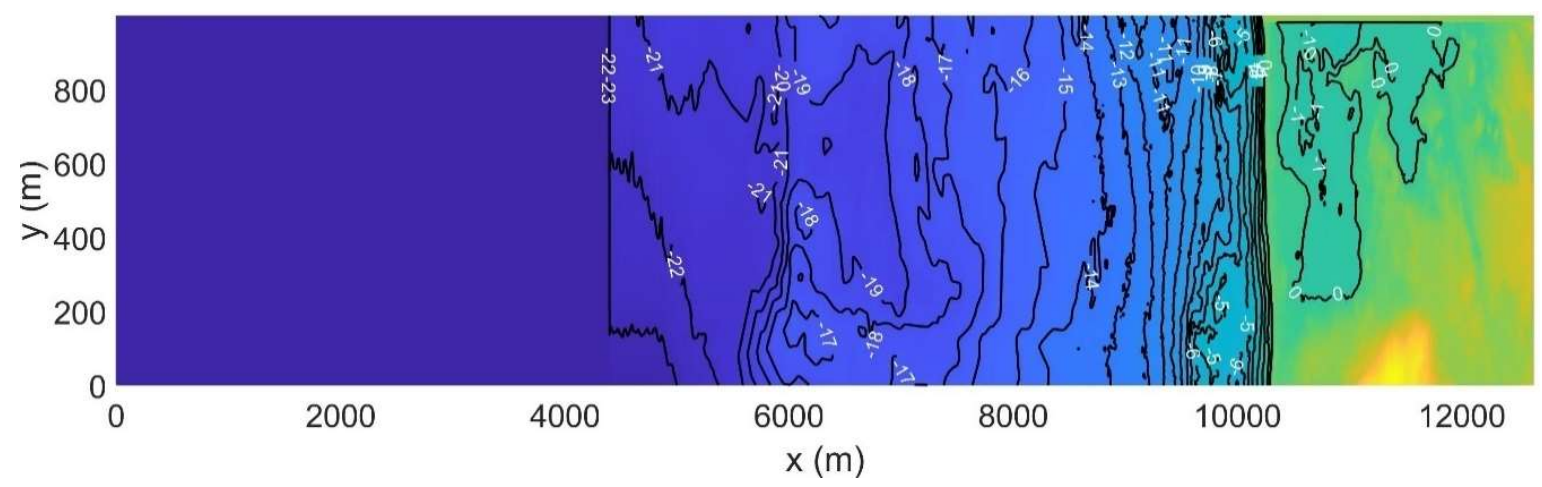

Figure 2: Contour plot of the study area. Contours are placed every 1 meter from $23 m$ depth offshore to the coastline (0 meters NAVD88).

The study area is exposed to the Block Island Sound and the Atlantic to the south, receiving high energy surf (Figure 3), and is the first line in defense against coastal storms and rising seas. Previous studies have demonstrated the importance of a heathy resilient barrier beach system to dampen waves during extreme events, as well as healthily evolve and migrate with erosion and sea level rise.

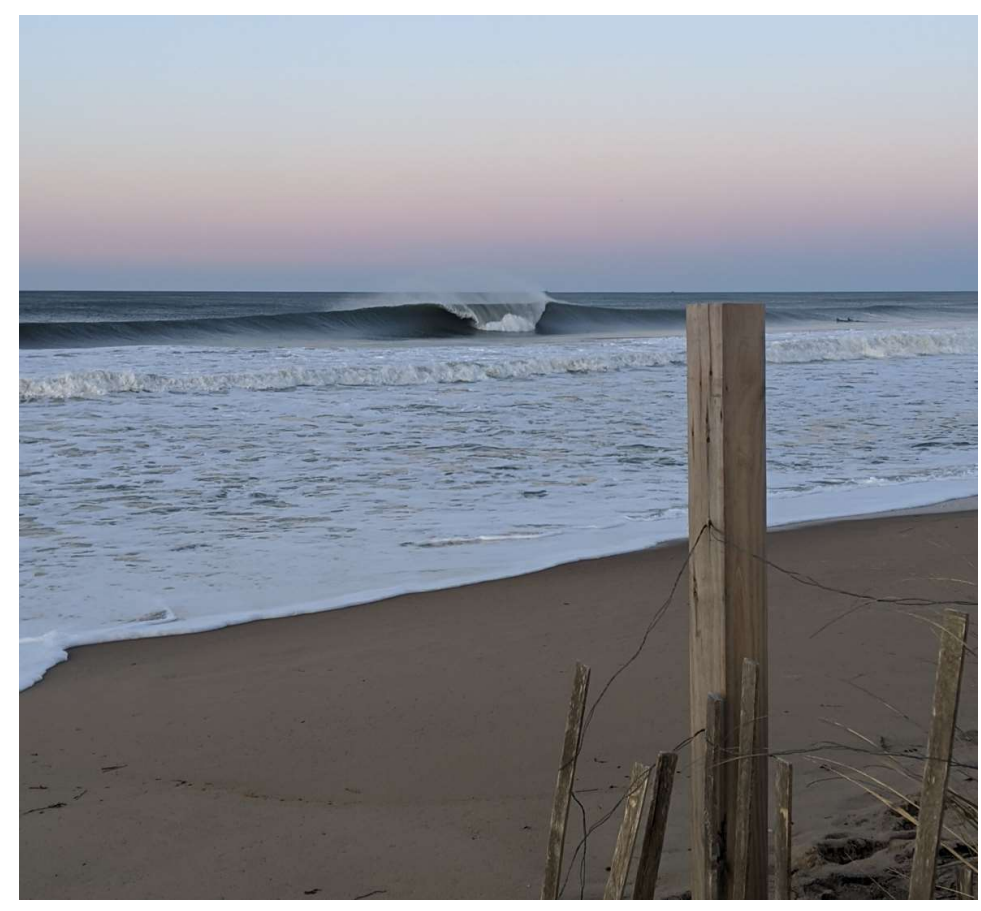

Figure 3: Large, high energy surf at Green Hill Beach, RI 


\section{Methodology}

The flow chart displayed in Figure 4 is representative of the FUNWAVE modeling process. Many inputs are available and compiled in an input file for the program. Once the simulation is begun, the inputs are read and the area to be modeled is divided into sub areas with each sub area placed on different processors for computational efficiency.

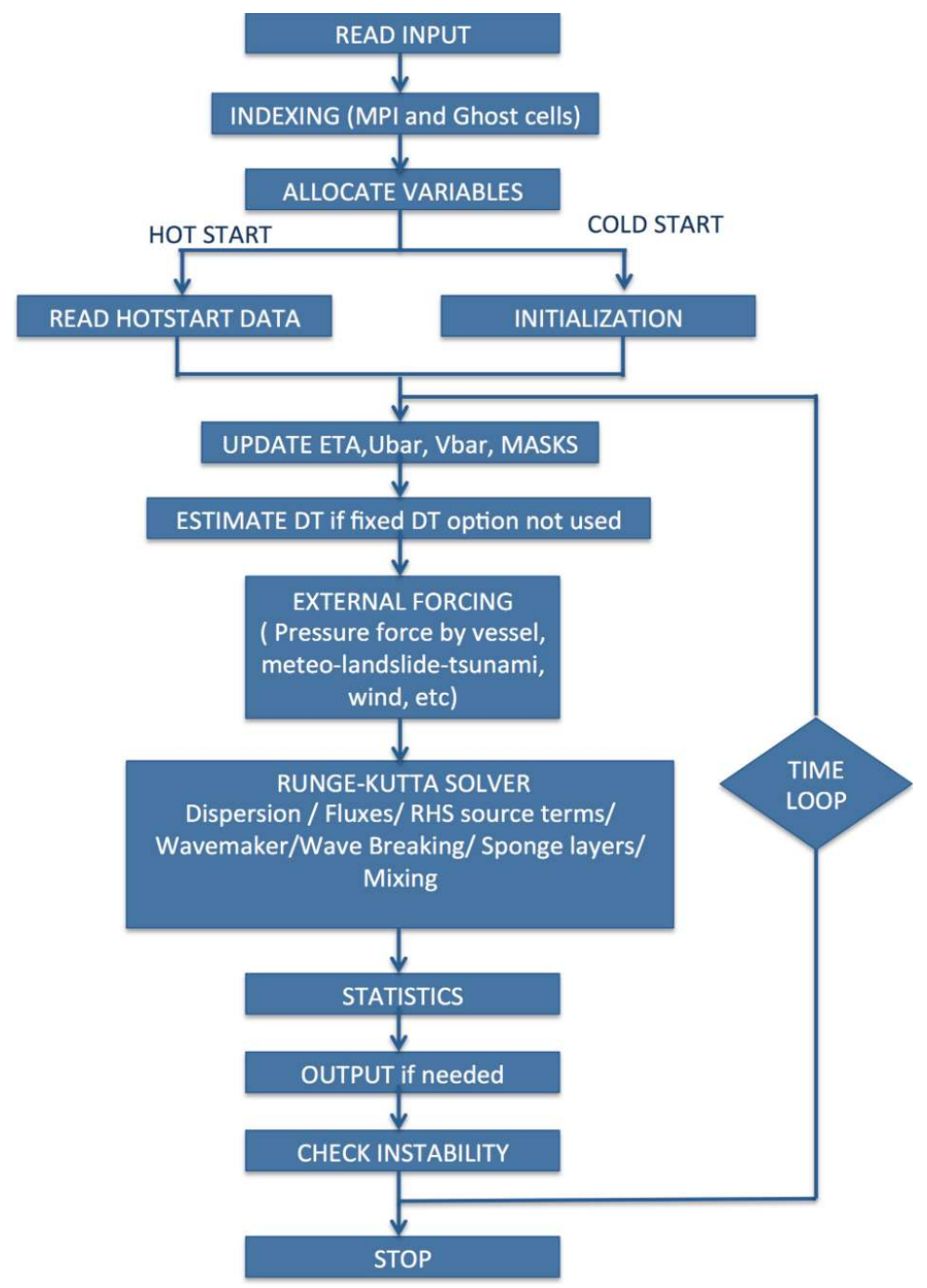

Figure 4: FUNWAVE flow chart (Shi et al., 2012) 
Simulations throughout this research were completed using the FUNWAVE model. To run the FUNWAVE model most efficiently access to a supercomputer cluster at the University of Rhode Island, Seawulf, and The Extreme Science and Engineering Discovery Environment (XSEDE) virtual system though the National Science Foundation (NSF), was obtained. The Seawulf computer cluster resource has no limitation on computational time and was utilized to learn FUNWAVE and complete experimental runs during the initial development of the model for our subject area.

Following model development, an application was submitted and accepted for 50,000 hours of computational time and $500 \mathrm{~GB}$ of storage on the Bridges supercomputer of the XSEDE system. These resources were used to run the developed model and produce the results displayed as a part of this thesis. The University of Rhode Island's Ocean Engineering group has utilized XSEDE resources in the past for tsunami propagation modeling with very positive results. Here, XSEDE resources are used in a similar fashion, running simulations over multiple processors as the FUNWAVE program was designed with efficient parallel MPI implementations. Modeling in FUNWAVE is comprised of an executable file compiled from its source code and several input text files consisting of identical grid dimensions. Calculations are performed on individual cell areas and passed along through the grid boundary layers at each prescribed time-step. FUNWAVE is less computationally efficient than models such as XBeach, as it models short waves in the time domain, creating the need for the XSEDE resource of multiple processors and allowing for a significant reduction of modeling run-time. 
A significant effort was devoted to pre-process the data necessary for the simulations: the built-up topography or Digital Elevation Model (DEM), the bathymetry and the land use data required to best represent the variable friction induced by the vegetation (Schambach et al., 2018). This allowed for the best representation of the hazard's impact, including erosion and wave changes with vegetation friction and impacts on structures. As each scenario produced a large quantity of output data, the outputs were received in binary format and processed using MATLAB. The outputs of the model include wave and water elevation, currents, suspended sediment and change in bed level. A sensitivity to the input parameters was addressed to assess their relative importance in the coastal processes. Relevant computational parameters were calibrated to optimize the accuracy of the FUNWAVE model prediction.

\subsection{FUNWAVE model setup}

The computational grid ( 2 by $2 \mathrm{~m}$ ) was set up to assess wave effects along the narrow study area, Green Hill Beach, and to capture the long infra-gravity waves impacting the shoreline. To do so, the grid was extended far enough offshore to allow wave grouping to occur (Lynett and Liu, 2005) resulting in a study grid of $(1000 \mathrm{~m}$ by $12640 \mathrm{~m}$ ) (Figure 1). The fine resolution is required to fully capture the wave spectrum since waves are propagating in the time domain.

The relevant input of bathymetry and friction were interpolated onto the grid using MATLAB. Input data, bathymetry and friction were provided by the RIGIS database (RIGIS, 2013). The bathymetry is a compilation of the most accurate NOAA Digital Elevation Model (DEM) improved with local LIDAR (Light Detection and Ranging) 
data resulting in a $10 \mathrm{~m}$ resolution bathymetry, and $1 \mathrm{~m}$ resolution topography. This data provides a high definition bathymetry and topography. The topography is a "built-up" DEM which includes the coastal structures. A significant effort was devoted to image processing to filter the undesired information in the built-up DEM (e.g. tree canopy). It resulted in a clean built up DEM where only the structures are conserved along the shoreline of the study area (Figure 5).

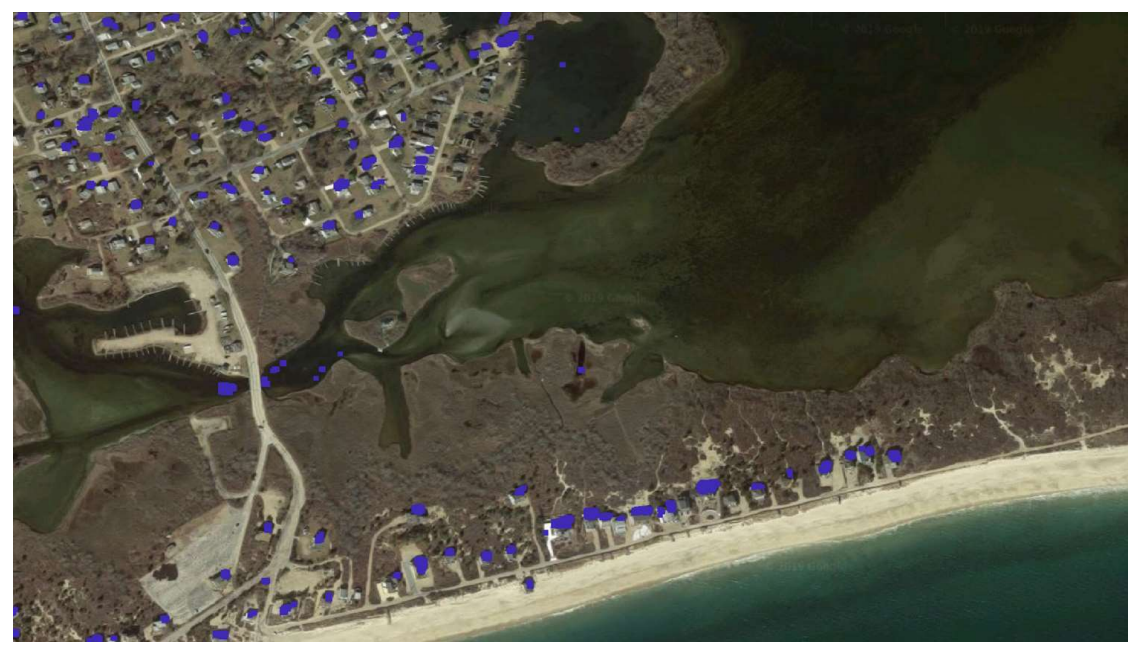

Figure 5: Example of image processing used to select structures from Google Earth. Purple marks are mostly representative of coastal homes.

Simulated erosion was compared to coastal erosion survey data (Schambach et al., 2018) and to the numerical work in progress of the current Master's thesis candidate, Jennifer Brandes, modeling a similar reef using the XBeach model.

The Hurricane Irene storm event is simulated using storm surge and wave spectral parameters in offshore boundary conditions (BC) at the offshore boundary of the FUNWAVE computational grid. These $\mathrm{BC}$ were estimated using the results of simulations with the coupled ADCIRC/ SWAN model over the entire North Atlantic region, and extracting the predicted storm surge and spectral parameters at the offshore edge of our computational domain (Torres et al., 2019). These representative values are 
the significant wave height (Hs) at the peak of the storm and the associated peak wave period (Tp). Figure 6 displays the location of the center of the offshore boundary as a red dot, with the nearest node from the (Torres et al., 2019) model as a green dot. A time series for the significant wave height (Hs) and peak wave period (Tp) were taken for the Hurricane Irene event at this location (Figure 7). The peak storm surge ( $\eta$ ) for the corresponding storm was taken from verified surge data at the wave buoy (Lon., Lat.): NOAA-44097 (-71.127, 40.999) (NOAA, 2020). The peak values for the storm were set as BC and initial condition for the FUNWAVE numerical wavemaker located at the offshore boundary. These $\mathrm{BC}$ used in representation of Hurricane Irene for the simulations are shown in Table 2.

The lateral BC, to the East and West of the study area, is set to periodic in the FUNWAVE model. This condition can be used for mostly straight coastlines, as in this study. With the periodic boundary condition turned on, anywhere wave breaking causes waves and currents to move laterally, towards the boundaries, water velocities moving at one lateral boundary are passed through to become an input on the opposite side. With the input waves normal to the domain in this study, this condition becomes most relevant in the nearshore region.

Table 2: Hurricane Irene Initial Wave Maker Conditions

\begin{tabular}{|c|c|c|c|}
\hline $\mathbf{H s}$ & $\mathbf{T p}$ & $\boldsymbol{\eta}$ & $\boldsymbol{\theta}$ \\
\hline $4.42 \mathrm{~m}$ & $13.3 \mathrm{~s}$ & $0.6 \mathrm{~m}$ & 0 \\
\hline
\end{tabular}




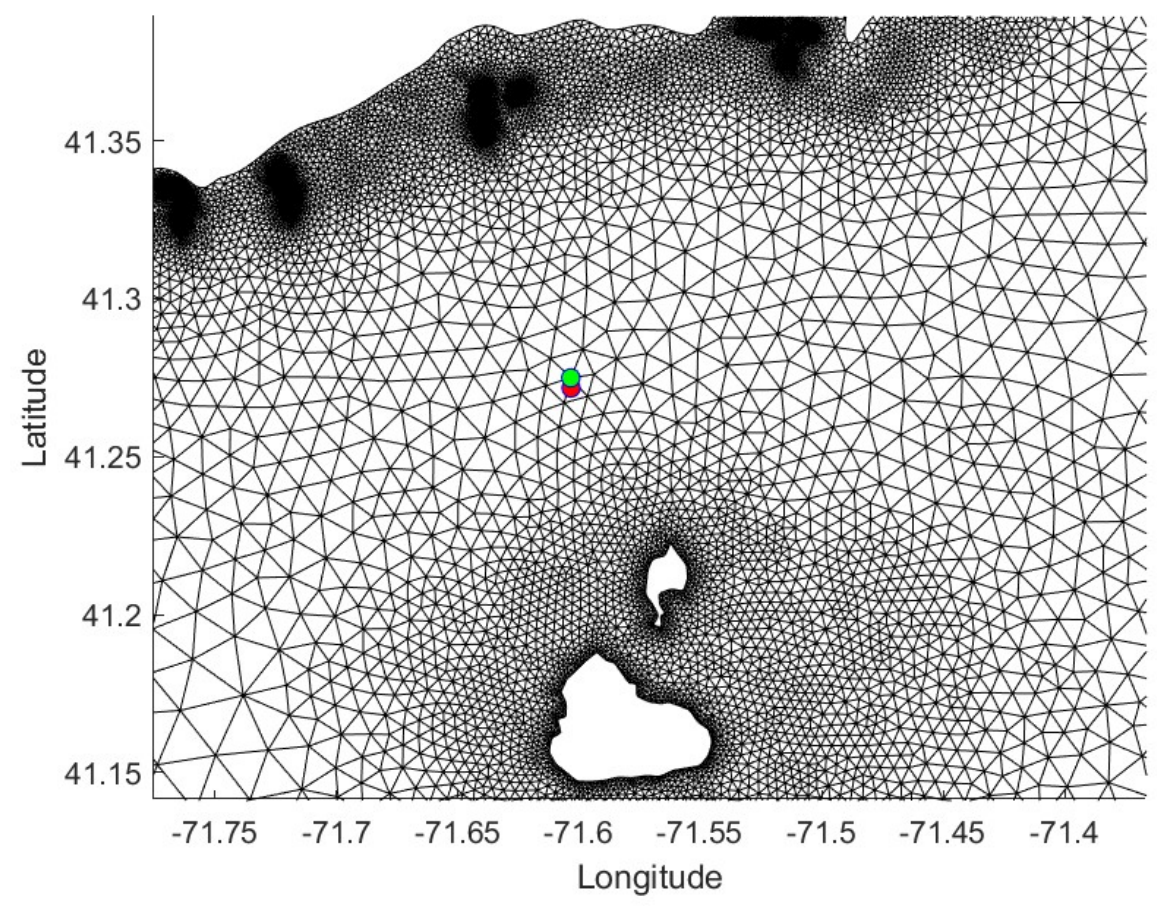

Figure 6: The Torres et al., 2019 grid showing the nearest ADCIRC data point location in (green) to the center of the offshore boundary for the current study (red)
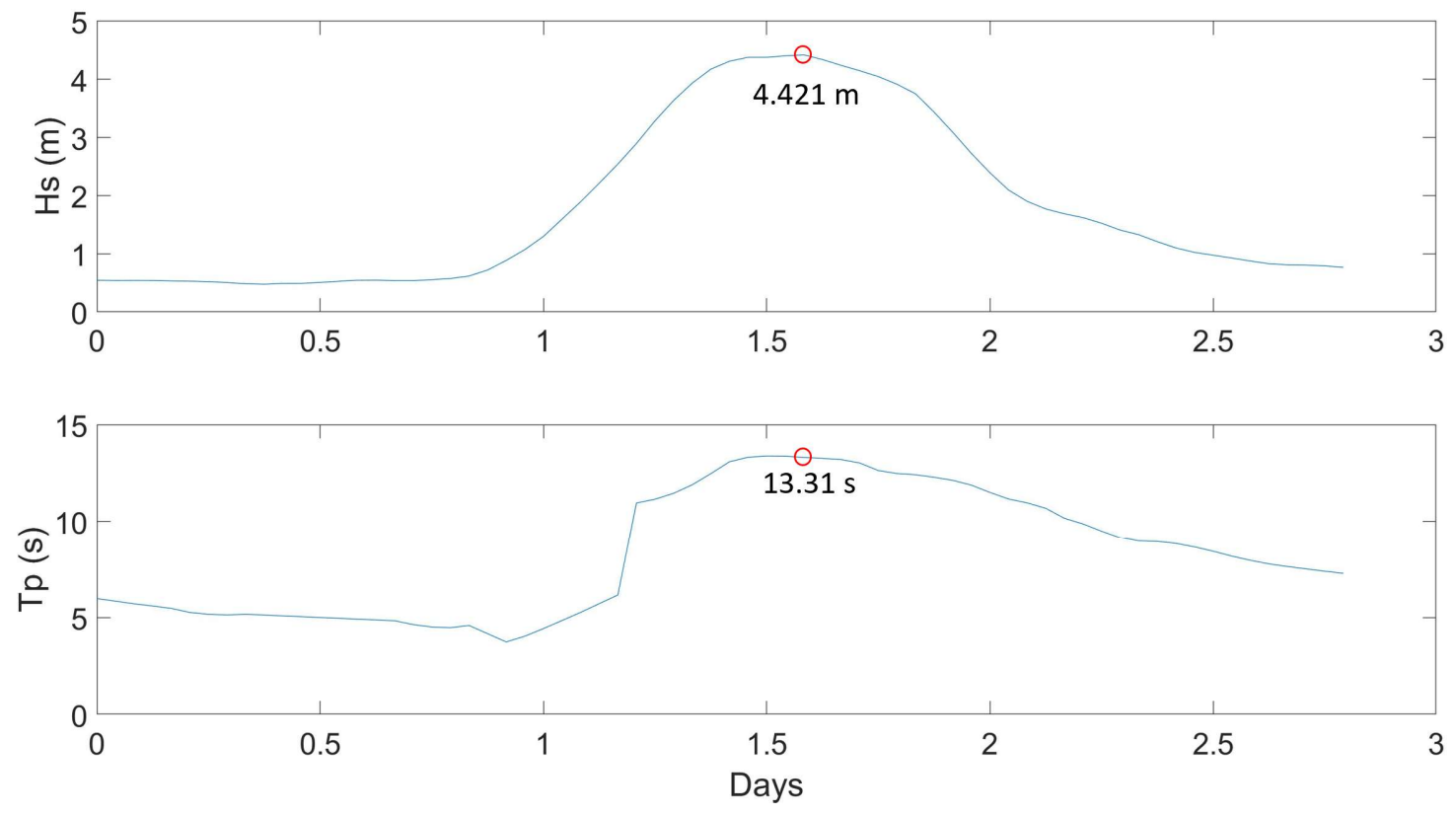

Figure 7: Significant wave height (Hm0) and peak period (Tp) taken at the location shown in Figure 6 from Torres et al. (2019) Hurricane Irene simulation results 


\subsection{FUNWAVE calibration}

The first portion of this thesis effort consists of the calibration of the hydrodynamic wave model, FUNWAVE at the study site using the historical storm Hurricane Irene.

First, we tested the convergence of the results to the grid size. The spectrum generated by the numerical wavemaker was compared to input spectrum.

A small and very long, $2 \times 2$ meter grid $(500 \times 6320)$ at the study area was used for this calibration and sensitivity study stage. However, such a small high grid discretization is not typically used in FUNWAVE, and standard input conditions resulted in abnormally large wave height results. The formation of large waves in the model occurred in both normal and simplified input conditions; in some instances, producing wave heights up to 5 times larger than the input wave height, causing the model to blow-up, initiating a simulation failure.

The source of the issue was identified as the combination of small grid sizing and large waves input into FUNWAVE, causing computational issues in the grid cell time steps. Consequently, a sensitivity study was conducted on the Courant-FriedrichsLewy (CFL) parameter, which describes how much information passes through grid cells in each time-step. A reduction in the CFL allows for more processing time of the partial differential equations in each time step for the $2 \times 2$ meter cells. Principally, the CFL parameter needs to be set low enough so that it allows the distance between grid points to be greater than the distance the solution travels is a timestep and carry all necessary information from the previous grid cell. Of the CFL values tested in the simulation, the lowest value of 0.15 produced a wave spectrum with a significant wave 
height most representative of the input value. Lower CFL values may also produce accurate wave outputs but are likely not worth the computational time loss. Table 3 displays the outcome for each of the four simulations conducted in refinement of the CFL parameter. For each simulation, only the CFL input parameter was altered. The significant wave height input for each simulation was 4.42 meters. As the simulations with larger CFL values failed early, the resulting maximum significant wave height was taken after 1400 s of simulation time and repeated for each simulation for comparison.

Table 3: CFL sensitivity study results

\begin{tabular}{|c|c|c|c|c|}
\hline Simulation & CFL & $\begin{array}{c}\text { Hs (m) } \\
(\mathbf{m a x} \text { at 1100s) }\end{array}$ & Runtime & $\begin{array}{c}\text { Simulation Time } \\
(\mathbf{s})\end{array}$ \\
\hline $\mathbf{1}$ & 0.5 & 22.13 & $\begin{array}{c}1 \mathrm{~h} 27 \mathrm{~m} \\
\text { Simulation Failure }\end{array}$ & 1400 \\
\hline $\mathbf{2}$ & 0.4 & 14.67 & $\begin{array}{c}2 \mathrm{~h} 46 \mathrm{~m} \\
\text { Simulation Failure }\end{array}$ & 1800 \\
\hline $\mathbf{3}$ & 0.3 & 8.53 & $\begin{array}{c}5 \mathrm{~h} \\
\text { User Terminated }\end{array}$ & 2600 \\
\hline $\mathbf{4}$ & 0.15 & 4.71 & $\begin{array}{c}13 \mathrm{~h} 11 \mathrm{~m} \\
\text { User Terminated }\end{array}$ & 3600 \\
\hline
\end{tabular}

To most accurately calculate wave amplitudes in individual grid cells the remaining simulations in this study use a CFL value of 0.15 . The reduction of the CFL comes at cost of simulation time, with a simulation using a CFL value of 0.5 running 4.5 times faster than an identical simulation with a value of 0.15 . The following figures (Figure 8 and Figure 9) depict the wave spectrums for both the CFL 0.5 and 0.15 case, respectively. It is important to note the scale below each plot and that the large waves in the CFL $=0.5$ case cause a simulation failure before the input wave spectrum reached the shoreline. 


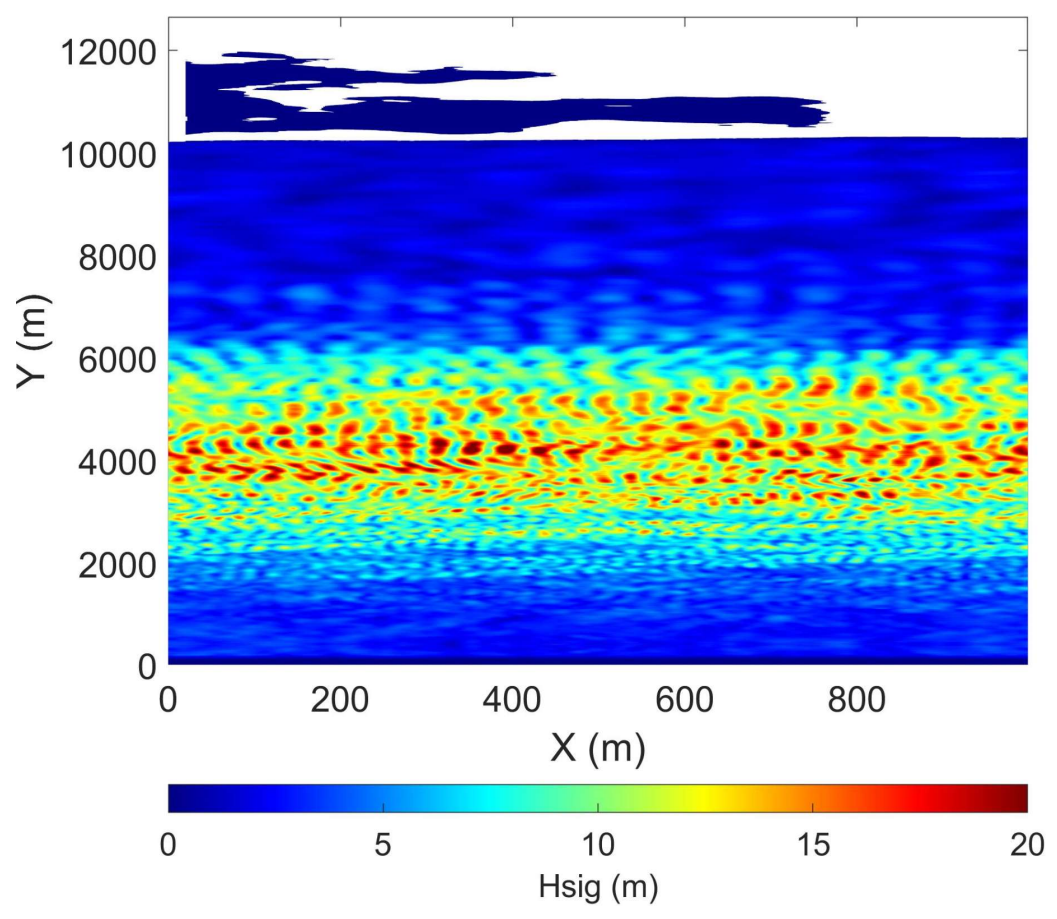

Figure 8: Study area showing the Hs (m) simulated during the sensitivity study of CFL for an input of $H s=4.42 \& C F L=0.5$. Timestep shown is after 1400 s of wave propagation

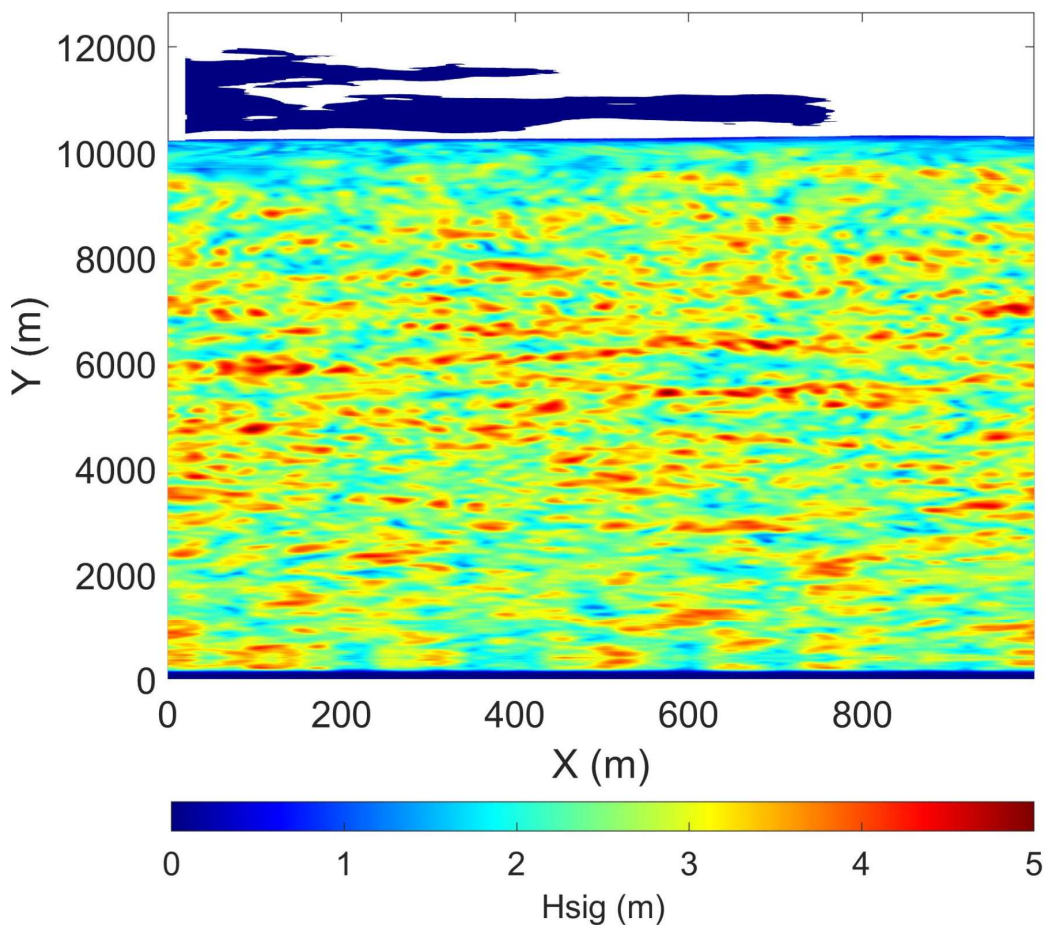

Figure 9: Study area showing the $H s(m)$ simulated during the sensitivity study of CFL for an input of $H s=4.42 \& C F L=0.15$. Timestep shown is after 3600 s of wave propagation 


\subsection{Simulation scenarios for unaltered conditions (no reef)}

The peak Hurricane Irene conditions are first utilized as the input to the FUNWAVE wavemaker for the case of an unaltered study area (no reef), representative of current conditions (Figure 10). A spatially variable friction grid, detailed over the land covering the study area was extracted from the Rhode Island Manning coefficient map (30 $\mathrm{m}$ resolution) and interpolated on the $2 \mathrm{~m}$ resolution computational grid (Schambach et al., 2018) (Figure 11). This spatially variable friction grid is used in the FUNWAVE simulation with any submerged area assumed to have a constant Manning coefficient of 0.02 . The friction grid becomes more important after the implementation of the reefs as the friction value at the reef is changed from 0.02 to 0.09 , more representative of a rough structure.

This simulation was completed for one hour of wave propagation. One hour was chosen for several reasons. First, with FUNWAVE being computationally consuming and supercomputer time limited, the shortest durations would best allow for multiple simulations to be run. Second, it has been shown (Grilli et al., 2020) that one hour of wavemaker input allows for the wave spectrum and currents to fully develop along the coastline, showing close to maximum wave heights that would normally be seen. While the FUNWAVE nonlinear wave representation would provide wave statistics slightly varying from linear wave theory, the linear wave theory can be useful to provide a rough estimate of the necessary number waves to represent a valid representative sea state. Accordingly, Equation 3 (Grilli et al., 2020; Forristall, 1978), relating maximum wave height, $\mathrm{H}_{\max }$, significant wave height, $\mathrm{H}_{\mathrm{s}}$, and number of waves, $\mathrm{J}$, shows that 
approximately 3000 waves, or 10 hours of simulation are required to capture $\mathrm{H}_{\max }$ (assuming that a Rayleigh distribution with $\mathrm{H}_{\max } \sim 2 \mathrm{H}_{\mathrm{s}}$ ). Using the same equation shows that 1 hour of simulation time in this study captures maximum waves height at least $84 \%$ of the $2 \mathrm{H}_{\mathrm{s}}$ value, which is close to the $1 \%$ of the highest wave $(\sim 1.8 \mathrm{Hs})$. Consequently, one hour of simulation was considered sufficient to represent a realistic sea state for this case study.

$$
H_{\text {max }}=0.707 \sqrt{\ln (J)} H_{s}
$$

Output values are recorded every 100 seconds across the entire study area and every 0.5 seconds at the station locations, displayed as white dots, in Figure 10. Most stations are placed nearshore in the surf zone and surrounding the location of the submerged reef implemented in the second study case. Station locations are identica! between the unaltered and submerged reef case for comparison purposes. 


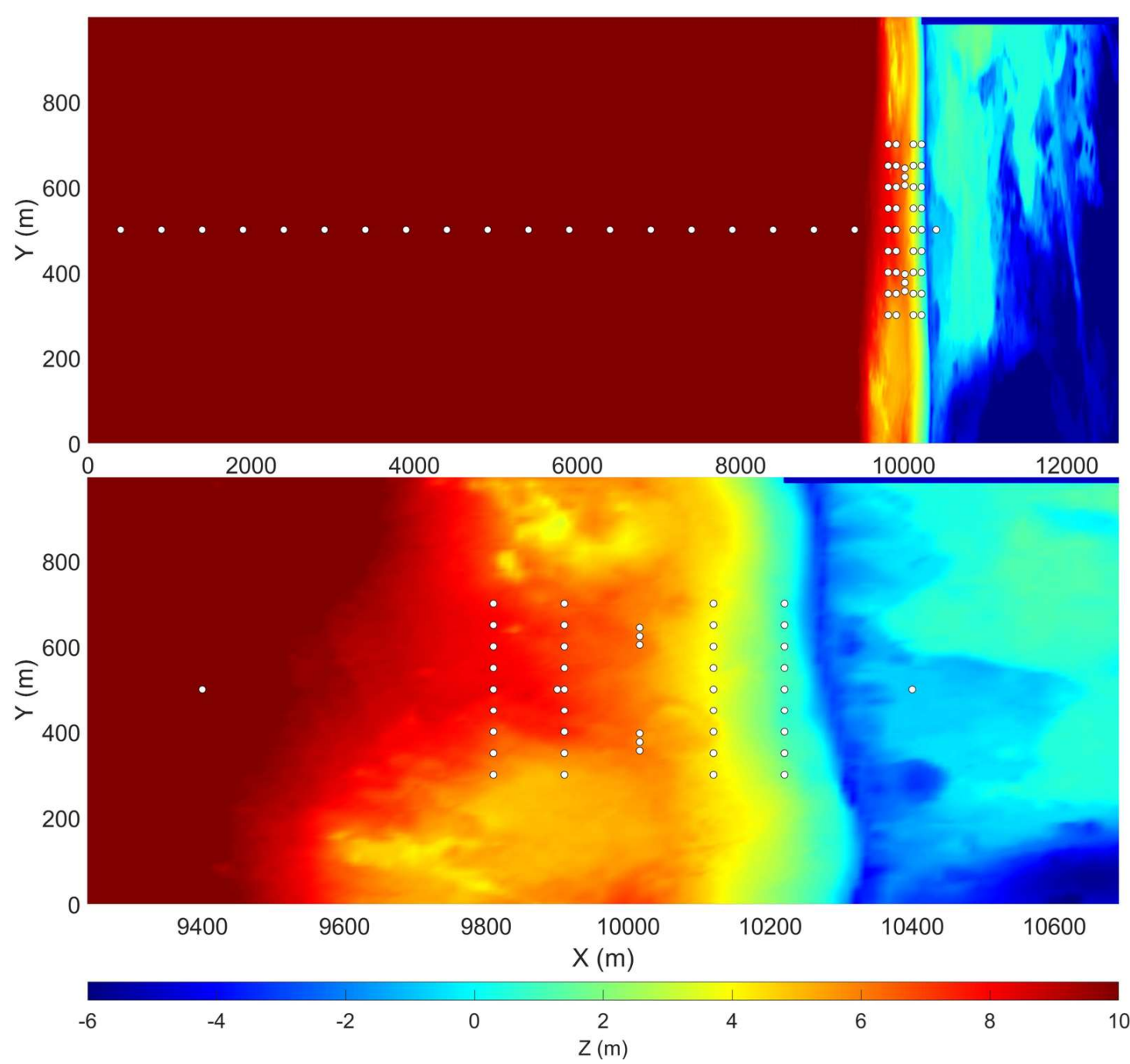

Figure 10: Unaltered (no reef) computational domain of the study area displaying the location of the virtual stations (Top); Zoomed in on the shoreline (Bottom); Colorbar shows the bathymetry/topography (m, MSL NAVD88) 


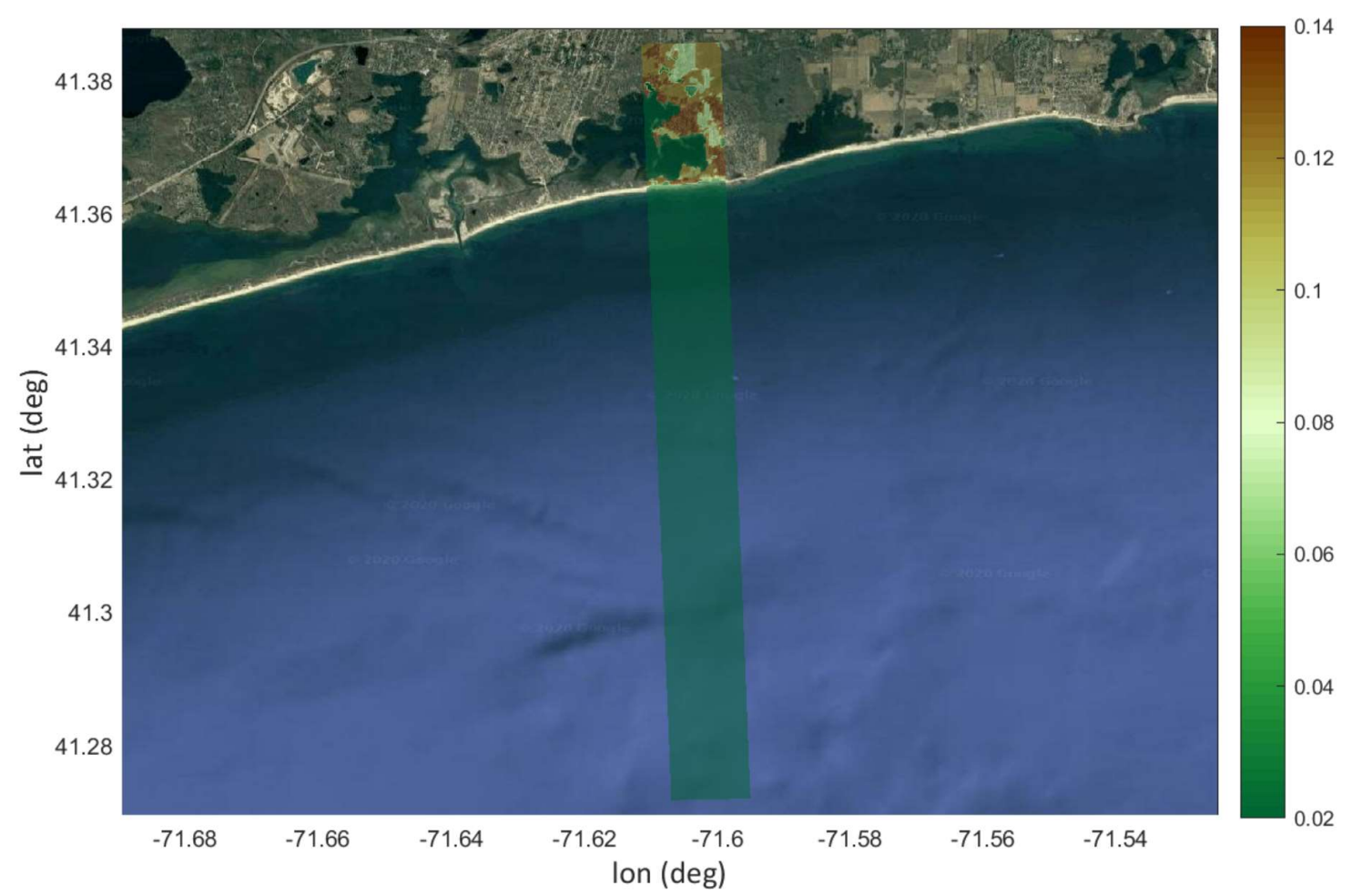

Figure 11: Manning friction coefficient over the study area (Schambach et al., 2018)

\subsection{Simulation scenarios with reef implementation}

The model is similarly forced with peak Hurricane Irene initial and boundary conditions for the study area altered with a submerged reef(Figure 12). Two submerged reef scenarios are performed with widths extending from 10 (scenario 1) to 30 meters (scenario 2); both are 200 meters long and centered in the study area, parallel to the shoreline. The reefs are located approximately 220 meters from the shoreline, placed in 6 meters of water with the reef crest located 1 meter below the still water level. The submerged friction grid remains the same as the unaltered version, with the exception of a modification to the area under the reef; changing it from a Manning coefficient of 0.02 to higher value of 0.09 (van Dongeren et al., 2013). 


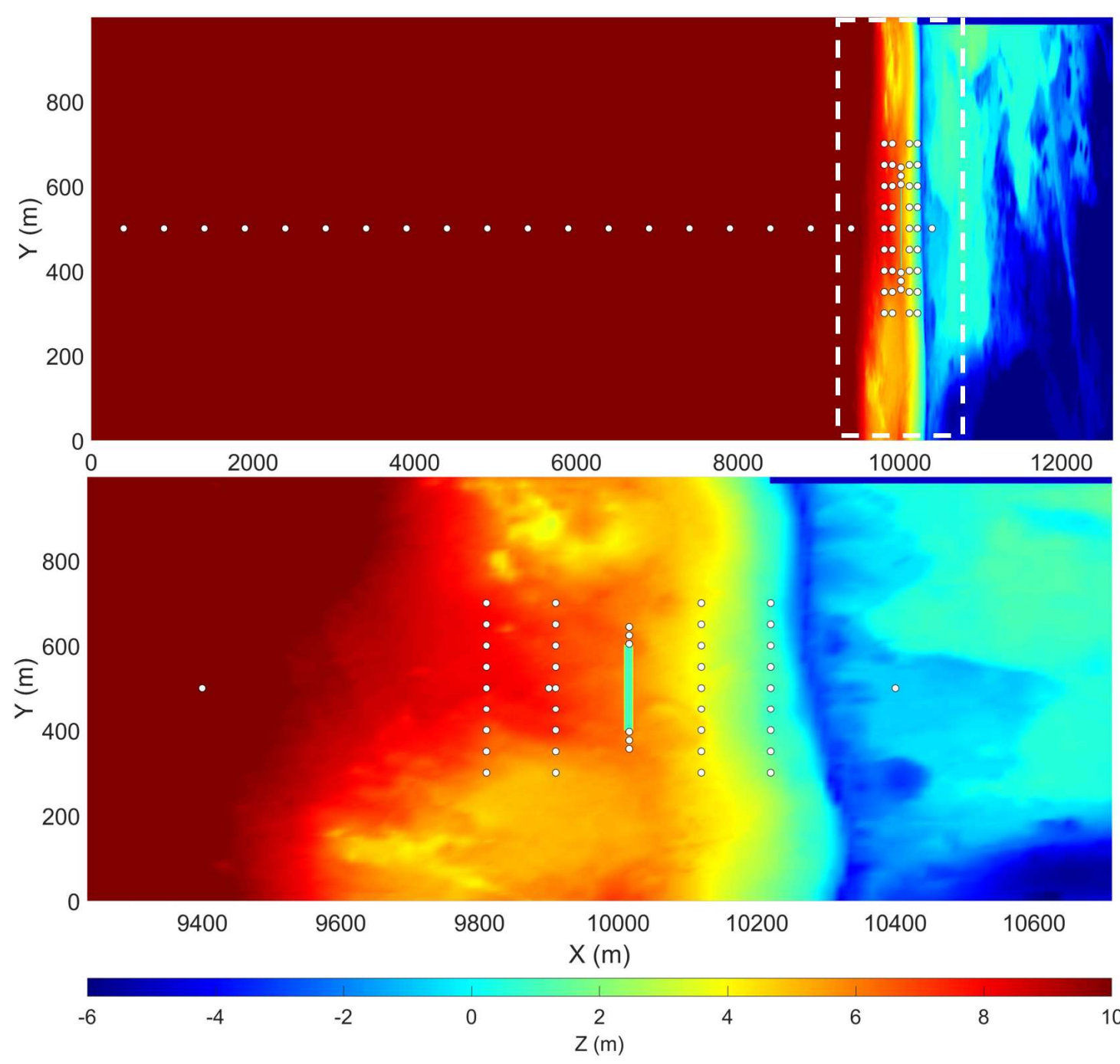

Figure 12: Reef Altered study area displaying the location of simulated buoy stations (Top); Zoomed on shoreline (Bottom) (m, NAVD88)

Adding a reef to the bathymetry changes the computational bathymetry. In particular, it creates steep bottom slopes around the reef which are likely to induce large water velocities causing numerical instabilities in FUNWAVE. To mitigate this numerical effect, an optional filtering scheme available in FUNWAVE was applied to the bathymetry. This filtering scheme smooths any bathymetry slope greater than 45 degrees. The sides of both reefs were reduced to slopes of approximately $5 / 6$ or 0.83 . 
This results in lowering the slopes of the implemented reefs resulting in 6 and 26 meters reef crest widths, and 18 and 38 meter base widths, for reef $\# 1$ and $\# 2$, respectively (Figure $13 \&$ Figure 14). Both reef areas were considered non-erodible in the FUNWAVE model.

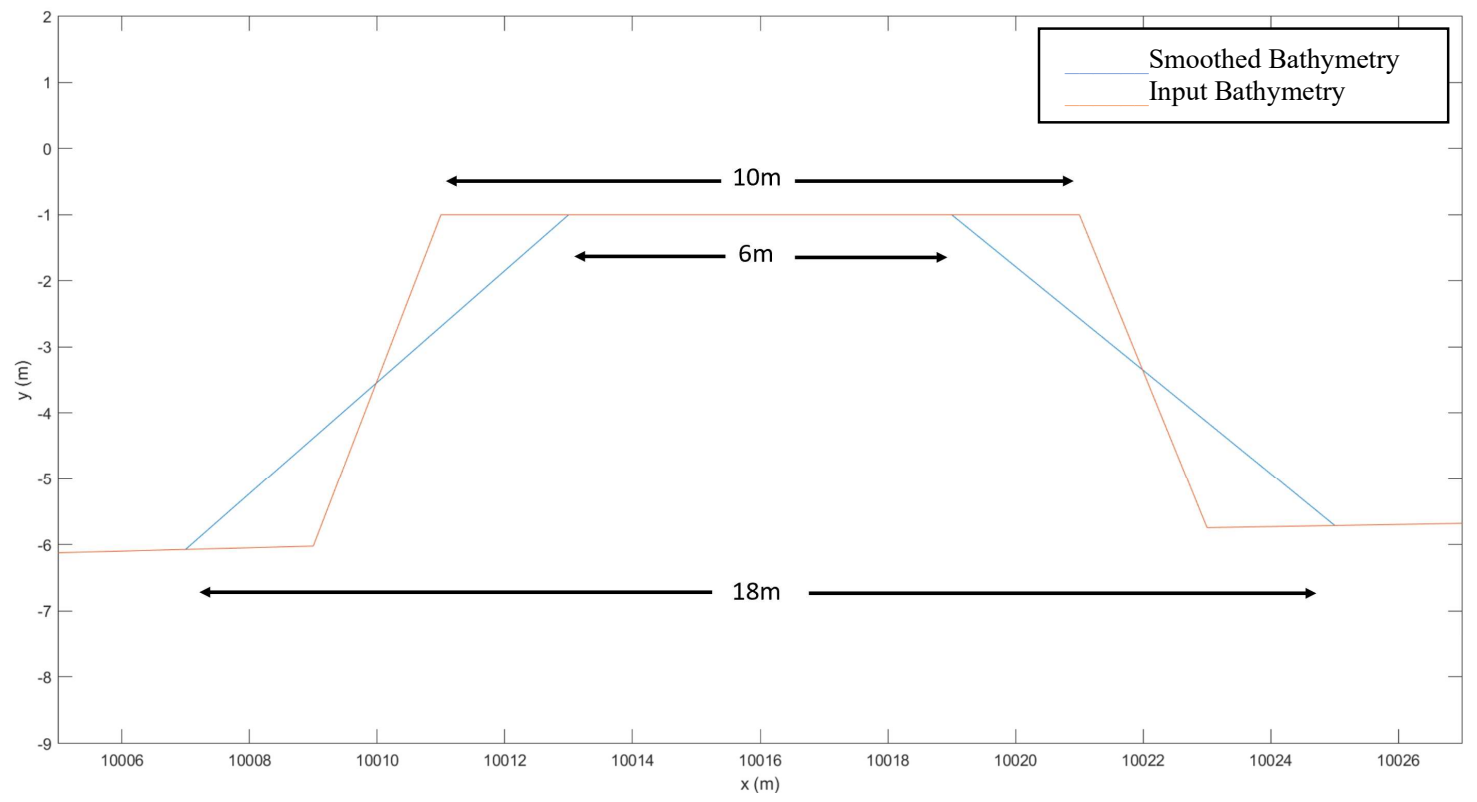

Figure 13: Input and smooth reef bathymetry comparison (Reef 1)

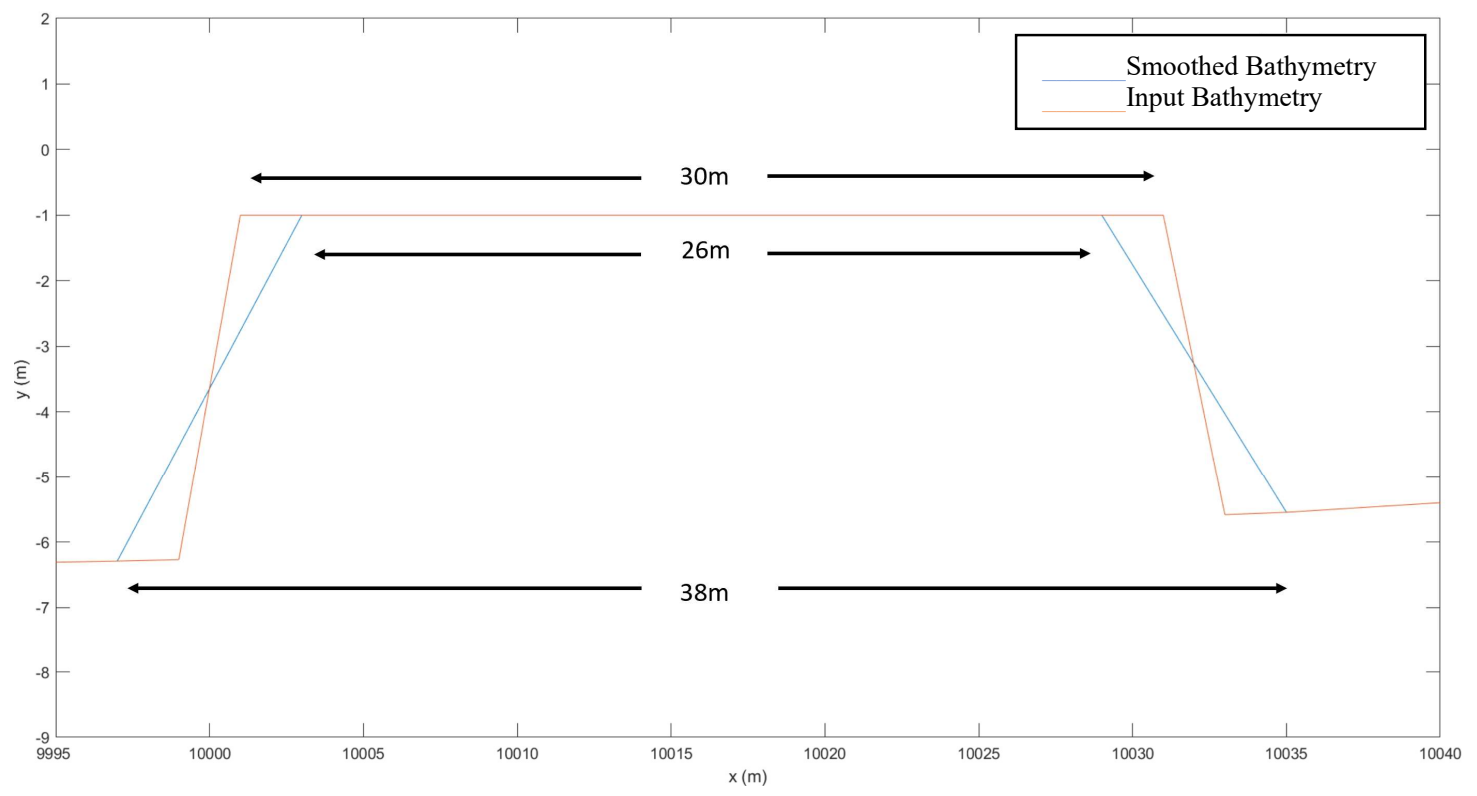

Figure 14: Input and smooth reef bathymetry comparison (Reef 2) 
Similar to the unaltered case, reef implemented simulations are completed for one hour of storm with grid and station output values recorded every 100 and 0.5 seconds, respectfully.

\subsection{Green Hill Study Site Simulation - Energy Transmission}

The efficiency of the submerged reef structure is first assessed by quantifying the wave energy reduction beyond the reef evaluating the wave transmission coefficient and the energy transmission coefficient based on transmitted energy calculations. Significant wave height is calculated offshore of and shoreward of the reef, at each of the station locations surrounding the reef. The wave transmission coefficient $\left(\mathrm{C}_{\mathrm{t}}\right)$ defined as the ratio of the offshore significant wave height, $\mathrm{H}_{\mathrm{i}}$ to the transmitted wave height shoreward of the reef, $\mathrm{H}_{\mathrm{t}}$, is written as:

$$
\mathrm{Ct}=\frac{H_{t}}{H_{i}}
$$

Both $\mathrm{H}_{\mathrm{i}}$ and $\mathrm{H}_{\mathrm{t}}$ are derived using the zero-up crossing method over the water elevation time series provided at the virtual station locations.

The wave energy is similarly estimated on both sides of the reef using the zeroup crossing significant wave height in the formulation of the mean wave energy for each unit of wave crest,

$$
E=\frac{1}{16} \rho g H_{s}^{2}
$$

with $\mathrm{E}$ as the wave energy $\left(\mathrm{J} / \mathrm{m}^{2}\right), \rho$ the water density $\left(\mathrm{kg} / \mathrm{m}^{3}\right), \mathrm{g}$ the acceleration of gravity $\left(\mathrm{m} / \mathrm{s}^{2}\right)$ and $\mathrm{H}_{\mathrm{s}}$ the significant wave height $(\mathrm{m})$. Values of $9.81 \mathrm{~m} / \mathrm{s}^{2}$ and 1025 $\mathrm{kg} / \mathrm{m}^{3}$ are used for acceleration due to gravity and seawater density, respectively. The 
energy transmission $(\Delta \mathrm{E})$ is estimated in absolute value as the difference of the energy offshore $(\mathrm{Ei})$ and beyond the reef $(\mathrm{Et})$ and as a relative coefficient $\left(\mathrm{C}_{\mathrm{E}}\right)$ being the ratio of Ei and Et. 


\section{Results and Discussion}

FUNWAVE's modeling outputs were post-processed using custom MATLAB code to provide maps and graphics and more easily understand model outcomes.

\subsection{Transmission Coefficient Comparison}

The values of the transmission coefficients for simulations with and without submerged reefs are compared in Table 4 . The virtual stations where these values were calculated are located as shown in Figure 15. The total energy transmission from offshore to the nearshore is also presented in Table 5. Comparisons show that the FUNWAVE model has a strong consistency producing offshore wave heights for the irregular wave case, with average offshore significant wave height values within 3 centimeters across simulations. It should also be noted that the energy reduction for the reef cases is significantly higher than that of the normal bathymetry case, with reef 2 providing the most energy reduction. This leads us to believe that wider reefs provide more energy reduction as width was the only variable that was changed between reefs.

Table 4: Relative wave and energy transmission across the submerged reef area

\begin{tabular}{|c|c|c|c|c|}
\hline Case & $\begin{array}{c}\mathrm{H}_{\mathrm{i}} \\
(100 \mathrm{~m} \text { seaward) }\end{array}$ & $\begin{array}{c}\mathrm{H}_{\mathrm{t}} \\
\text { (100m shoreward) }\end{array}$ & $\mathrm{C}_{\mathrm{t}}$ & $\Delta \mathbf{E}$ \\
\hline Normal & $2.38 \mathrm{~m}$ (Sta. 2) & $2.29 \mathrm{~m}$ (Sta. 3) & 0.96 & $264 \mathrm{~J} / \mathrm{m}^{2}$ \\
\hline Reef 1 & $2.28 \mathrm{~m}$ (Sta. 2) & $1.70 \mathrm{~m}$ (Sta. 3) & 0.75 & $1,451 \mathrm{~J} / \mathrm{m}^{2}$ \\
\hline Reef 2 & 1.95m (Sta. 2) & $1.51 \mathrm{~m}$ (Sta. 3) & 0.77 & $957 \mathrm{~J} / \mathrm{m}^{2}$ \\
\hline Normal & $2.25 \mathrm{~m}($ Sta. 6$)$ & $2.31 \mathrm{~m}$ (Sta. 7) & 1.03 & $-172 \mathrm{~J} / \mathrm{m}^{2}$ \\
\hline Reef 1 & $2.22 \mathrm{~m}($ Sta. 6$)$ & $1.60 \mathrm{~m}$ (Sta. 7) & 0.72 & $1,488 \mathrm{~J} / \mathrm{m}^{2}$ \\
\hline Reef 2 & $2.09 \mathrm{~m}($ Sta. 6$)$ & $1.36 \mathrm{~m}$ (Sta. 7) & 0.65 & $1,583 \mathrm{~J} / \mathrm{m}^{2}$ \\
\hline Normal & $2.11 \mathrm{~m}($ Sta. 10$)$ & $2.34 \mathrm{~m}$ (Sta. 11) & 1.11 & $-643 \mathrm{~J} / \mathrm{m}^{2}$ \\
\hline Reef 1 & $2.30 \mathrm{~m}$ (Sta. 10$)$ & $1.81 \mathrm{~m}($ Sta. 11$)$ & 0.79 & $1,266 \mathrm{~J} / \mathrm{m}^{2}$ \\
\hline Reef 2 & $2.31 \mathrm{~m}$ (Sta. 10$)$ & $1.30 \mathrm{~m}($ Sta. 11$)$ & 0.56 & $2,291 \mathrm{~J} / \mathrm{m}^{2}$ \\
\hline Normal Average: & $2.26 \mathrm{~m}$ & $2.31 \mathrm{~m}$ & 1.03 & $-184 \mathrm{~J} / \mathrm{m}^{2}$ \\
\hline Reef 1 Average: & $2.26 \mathrm{~m}$ & $1.70 \mathrm{~m}$ & 0.75 & $1,402 \mathrm{~J} / \mathrm{m}^{2}$ \\
\hline Reef 2 Average: & $2.12 \mathrm{~m}$ & $1.39 \mathrm{~m}$ & 0.66 & $1,610 \mathrm{~J} / \mathrm{m}^{2}$ \\
\hline
\end{tabular}


Table 5: Total offshore to nearshore wave and energy transmission

\begin{tabular}{|c|c|c|c|c|}
\hline Case & $\begin{array}{c}\mathrm{H}_{\mathrm{i}} \\
(200 \mathrm{~m} \text { seaward }) \\
\end{array}$ & $\begin{array}{c}\mathrm{H}_{\mathrm{t}} \\
(200 \mathrm{~m} \text { shoreward) }\end{array}$ & $\overline{C_{t}}$ & $\Delta \mathbf{E}$ \\
\hline Normal & $2.50 \mathrm{~m}($ Sta. 1$)$ & $1.25 \mathrm{~m}($ Sta. 4$)$ & 0.50 & $2,946 \mathrm{~J} / \mathrm{m}^{2}$ \\
\hline Reef 1 & $2.45 \mathrm{~m}$ (Sta. 1) & $1.30 \mathrm{~m}$ (Sta. 4) & 0.53 & $2,710 \mathrm{~J} / \mathrm{m}^{2}$ \\
\hline Reef 2 & $2.52 \mathrm{~m}$ (Sta. 1) & $1.11 \mathrm{~m}$ (Sta. 4) & 0.44 & $3,217 \mathrm{~J} / \mathrm{m}^{2}$ \\
\hline Normal & $2.40 \mathrm{~m}$ (Sta. 5) & $1.40 \mathrm{~m}($ Sta. 8$)$ & 0.58 & $2,388 \mathrm{~J} / \mathrm{m}^{2}$ \\
\hline Reef 1 & $2.32 \mathrm{~m}$ (Sta. 5) & $1.21 \mathrm{~m}($ Sta. 8$)$ & 0.52 & $2,462 \mathrm{~J} / \mathrm{m}^{2}$ \\
\hline Reef 2 & $2.36 \mathrm{~m}$ (Sta. 5) & $1.18 \mathrm{~m}$ (Sta. 8) & 0.50 & $2,625 \mathrm{~J} / \mathrm{m}^{2}$ \\
\hline Normal & $2.18 \mathrm{~m}$ (Sta. 9) & $1.27 \mathrm{~m}$ (Sta. 12) & 0.58 & $1,973 \mathrm{~J} / \mathrm{m}^{2}$ \\
\hline Reef 1 & $2.30 \mathrm{~m}$ (Sta. 9) & $1.25 \mathrm{~m}$ (Sta. 12) & 0.54 & $2,343 \mathrm{~J} / \mathrm{m}^{2}$ \\
\hline Reef 2 & $2.11 \mathrm{~m}$ (Sta. 9) & $1.08 \mathrm{~m}$ (Sta. 12) & 0.51 & $2,065 \mathrm{~J} / \mathrm{m}^{2}$ \\
\hline Normal Average: & $2.36 \mathrm{~m}$ & $1.31 \mathrm{~m}$ & 0.55 & $2,436 \mathrm{~J} / \mathrm{m}^{2}$ \\
\hline Reef 1 Average: & $2.36 \mathrm{~m}$ & $1.25 \mathrm{~m}$ & 0.53 & $2,505 \mathrm{~J} / \mathrm{m}^{2}$ \\
\hline Reef 2 Average: & $2.33 \mathrm{~m}$ & $1.12 \mathrm{~m}$ & 0.48 & $2,636 \mathrm{~J} / \mathrm{m}^{2}$ \\
\hline
\end{tabular}

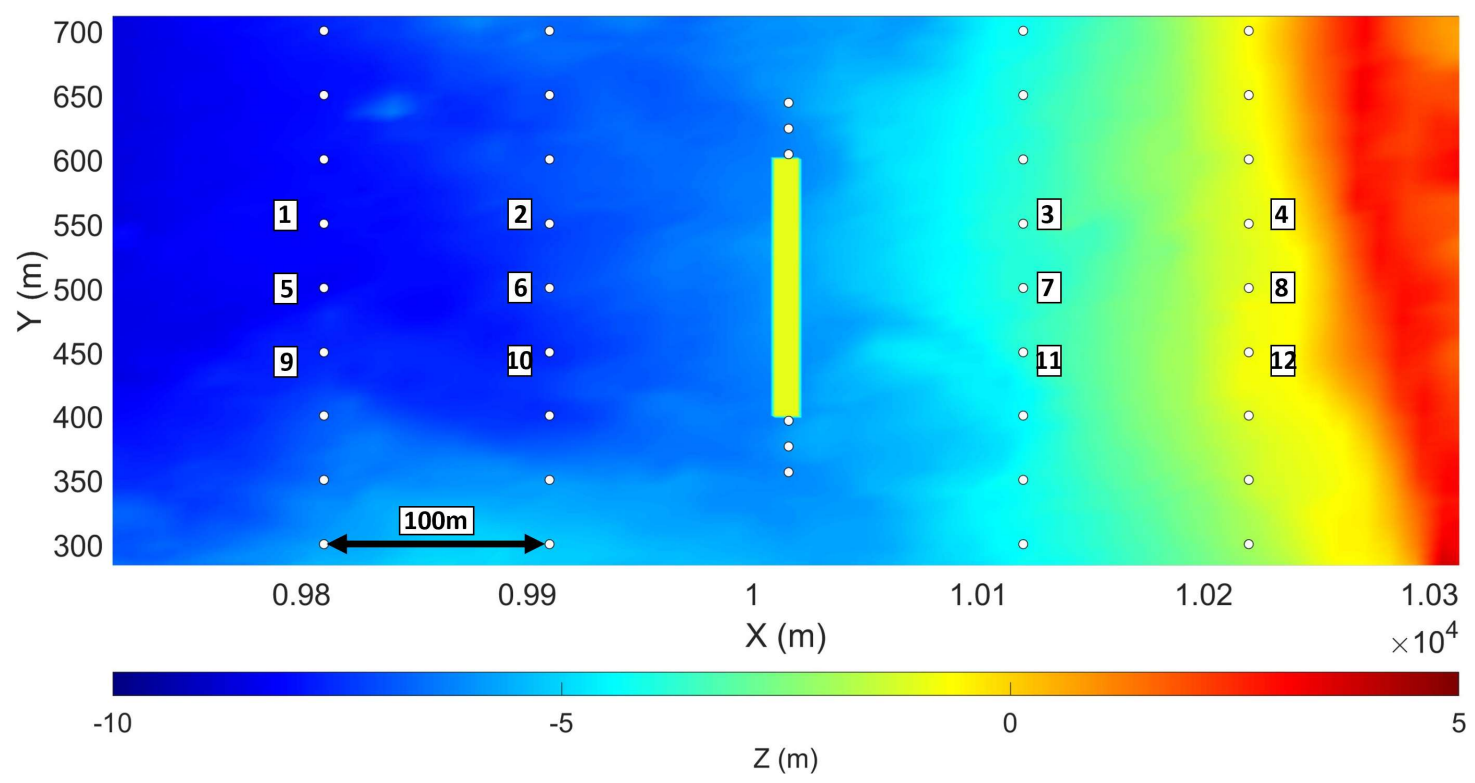

Figure 15: Station locations for data collection. Data at each white dot was collected every 0.5 seconds during the simulation. Numbers represent stations used in transmission and energy calculations.

The resulting average transmission coefficient found in this case study across reef 1 and reef 2 are 0.75 and 0.66 , respectively. These values are approximately $12 \%$ to $22 \%$ less than the value of 0.85 estimated in the literature for solitary waves (Grilli et al., 1994), proving that the reef design provides a good energy reduction for the study area. 
The solitary case study addressed a similar issue, but solely for solitary waves and was performed using numerical and laboratory experiments for a large range of wave heights and reef depths (including immerged and emerged scenarios). Results are recalled in Figure 16, which shows the transmission coefficient values as a function of the non-dimensional (ND) reef water depth and the ND wave height (both wave height and reef height are scaled by the water depth). Values greater than 1 show emerged breakwater cases in which the best results (low transmission coefficient) are obtained for the highest reef elevations and smallest waves.

In our numerical experiment, we consider a full irregular wave train and results are expected to vary from the solitary wave experiment. However, since we could not find similar literature on irregular waves, our results are best compared and put into perspective using the solitary experiment in Figure 16. Results indicate that the energy of an irregular wave train would be reduced more significantly than that expected based on solitary waves results. Based on the solitary waves results, optimal conditions for a submerged reef would be for a reef extending across $90 \%$ of vertical water column and more significantly for waves higher than $50 \%$ of the local water depth $(60 \%$ transmission; preventing $40 \%$ of the energy from propagating landward). Our studies reefs are positioned in 6 meters of water expending up to $1 \mathrm{~m}$ from the surface (not accounting for $0.6 \mathrm{~m}$ of surge), covering about $76 \%$ of the water column. Notice that the value of the transmission coefficient $\mathrm{Ct}=0.66$ obtained for reef 2 , is close to the expected optimal value in the solitary wave experiment, and yet the reef is relatively deep; one could expect better results for a reef closer to the sea surface. 
Note that, besides simulating a full wave train of irregular waves, the current simulations model the reflection and breaking induced by the reef, where the friction was also assumed negligible in the solitary wave experiment.

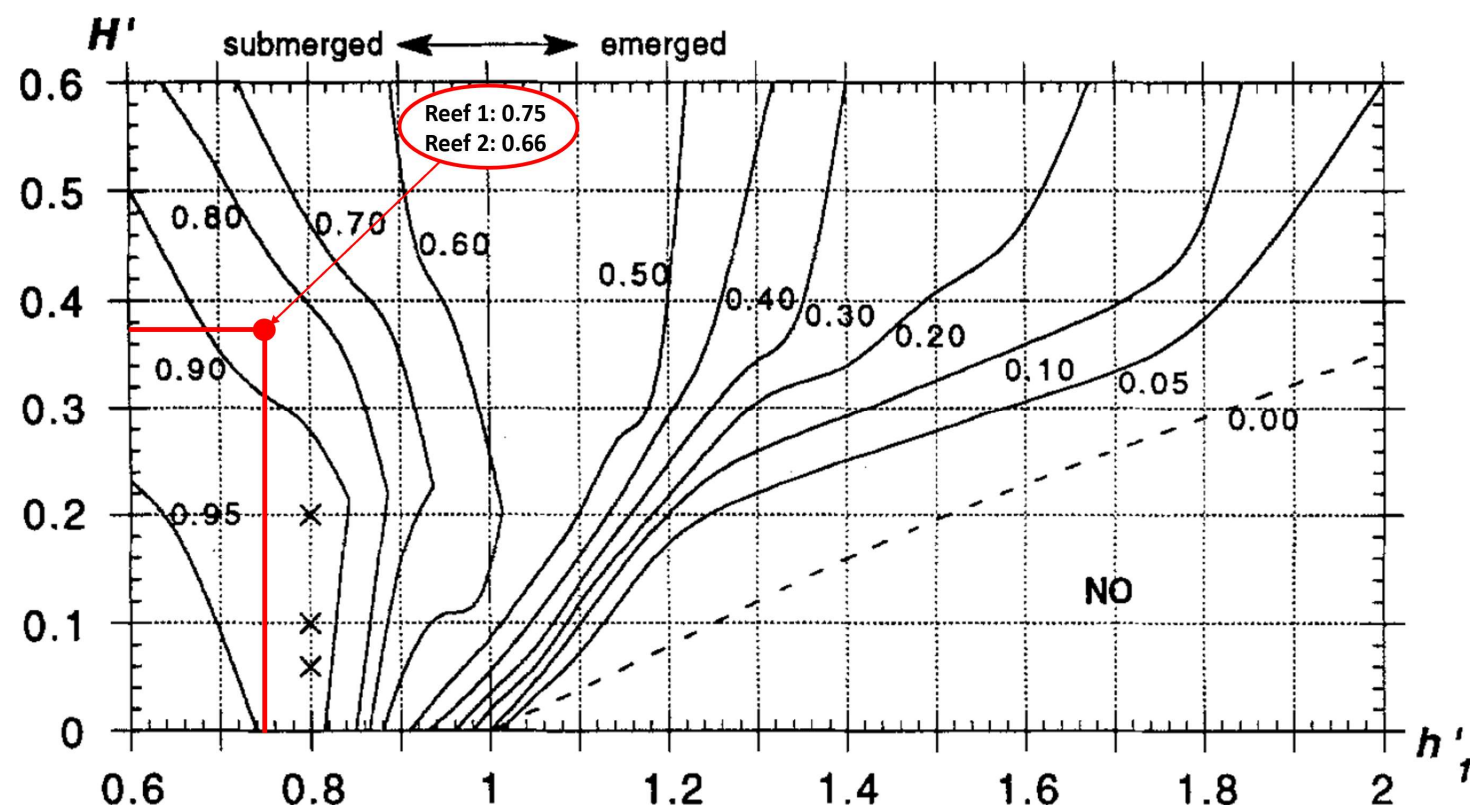

Figure 16: Reef transmission coefficient values and the theoretical transmission coefficient location (red dot) on FIG 3 from (Grilli et al., 1994). Here, $h$ ' ${ }_{1}$ is the reef height/water depth and $H^{\prime}$ is wave height/water depth. Values less than 1 on the $x$ axis represent a submerged reef

The comparison of the transmission coefficient value determined in this study with results from (Grilli et al., 1994) show a transmission reduction of $12 \%$. While (Grilli et al., 1994) had simulated the reef effect for solitary waves, the current study simulates an irregular, dispersive and non-linear wave train. The error of the model in (Grilli et al., 1994) overestimates the transmission by $2-7 \%$. Including this error would set our transmission coefficient to a value 14 to $21 \%$ less than the best estimates from solitary waves experiments. As expected, the newly estimated values for the transmission coefficient are significantly different and more optimistic (showing less transmission) 
when using a complex model which uses 2-D complete physics of the processes involved.

\subsection{Nearshore Velocity Comparison}

It is evident from the comparison of the maps shown in Figure 17 that the deployment of a submerged reef along the coastline has a significant effect on currents. The black lines in the figure represent current direction and strength with longer velocity vectors representative of stronger current. The reef reduces current velocities directly onshore of the reef, and greatly increases current velocities at the reef location. 

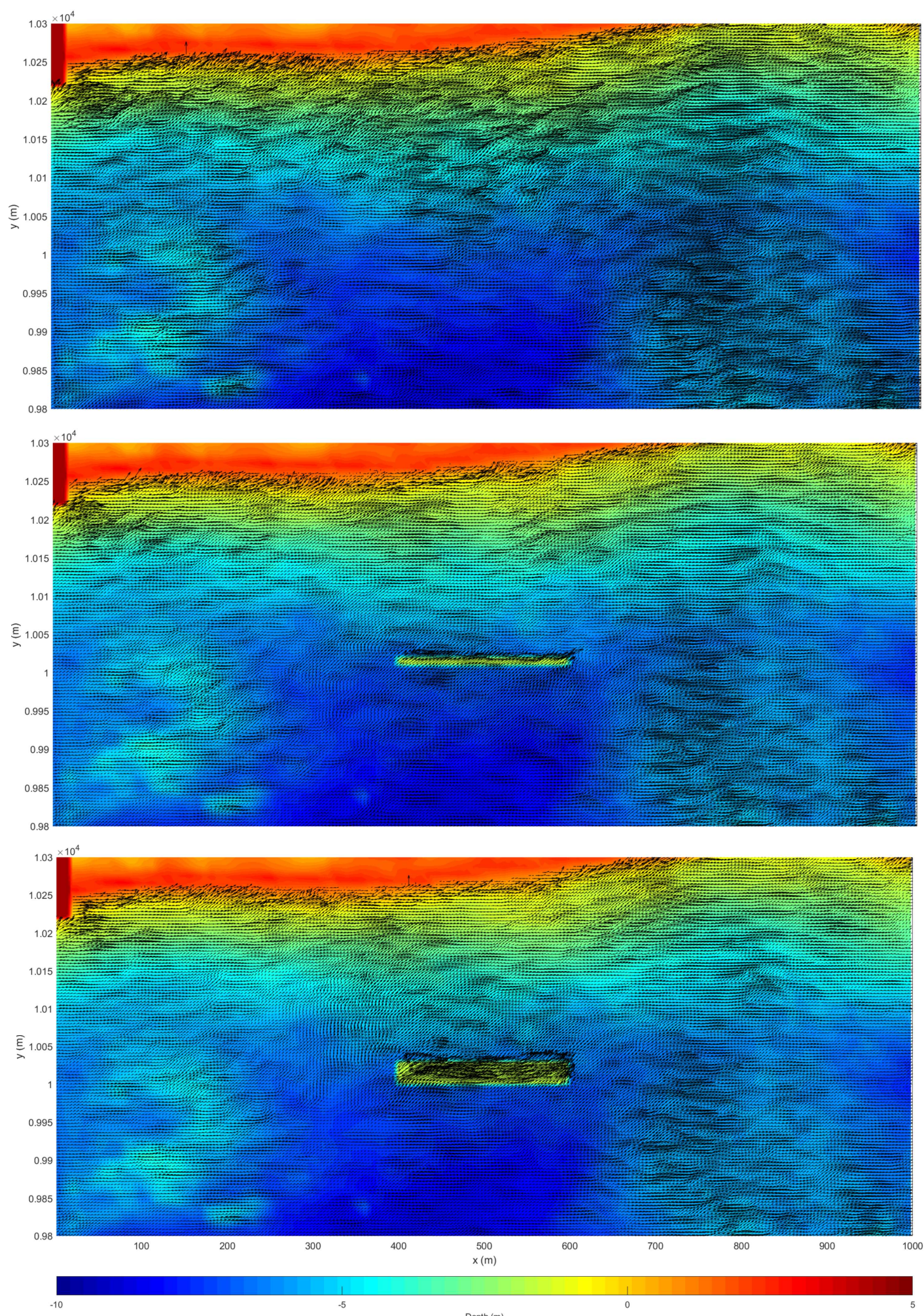

Figure 17: Bathymetry color map overlaid with max current velocity vectors averaged over all time steps. Velocity vectors appear as lines with areas of stronger current represented by darker shaded areas; No reef (a); Reef 1 (b); Reef 2 (c) 
To better visualize the reduction in velocity, Figure 18 displays a colormap highlighting the difference between the normal condition velocities and the velocities after implementation of each reef. Positive values indicate a reduction in velocity after reef implementation. Note the clear trend of negative values offshore of the reef (dark colors) and positive values (light colors) shoreward. Negative values are higher and more concentrated offshore, where positive values are smaller and more evenly dispersed shoreward of the reef.

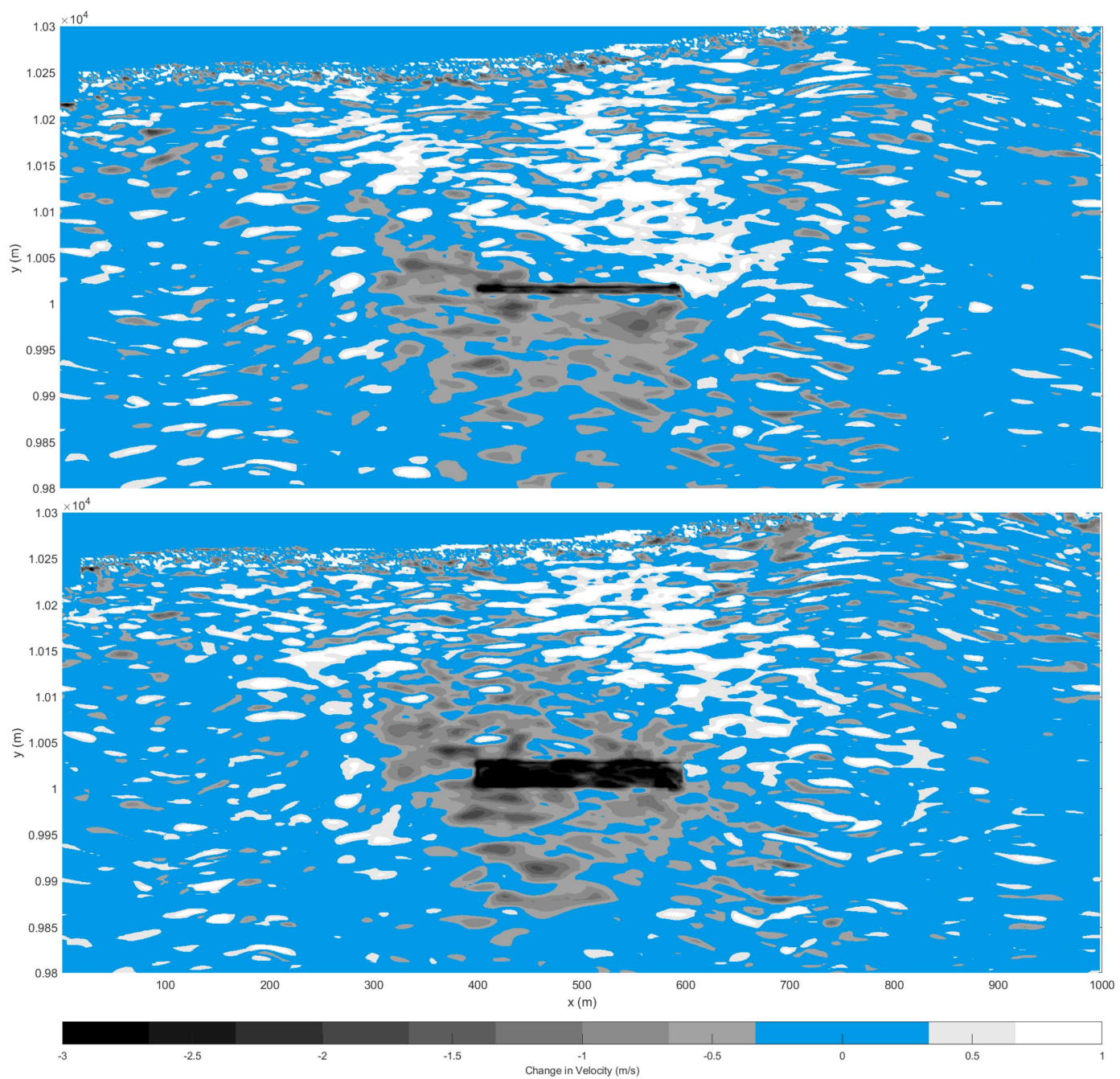

Figure 18: Velocity difference between simulations (no reef case - reef case). Positive values indicate lower velocities after the reef was introduced. Reef 1 (top); Reef 2 (bottom) 


\subsection{Power Density Spectrum Comparison}

To best resolve wave energy reduction by the reef, reflection was calculated by solving for the offshore energy difference with and without the reef. The power density spectrum shown in Figure 19 displays this difference at 3 station locations $200 \mathrm{~m}$ offshore each simulated reef. Estimates from this approach show that the reef caused an offshore wave energy decrease of $45 \mathrm{~J} / \mathrm{m}^{2}$ and an increase of $6 \mathrm{~J} / \mathrm{m}^{2}$ for reef 1 and 2 , respectively. Only the $6 \mathrm{~J} / \mathrm{m}^{2}$ increase in wave energy offshore indicates reflection in the reef 2 case, however both values are extremely low, accounting for only 0.4 to 3.2 percent of the total energy reduction transmitted shoreward of the reefs. This means there is no offshore reflection caused by the reefs in these simulations and the small values shown here most likely are only exposing the difference between simulations and not a real change caused by the reefs.

These low values, representative of no reflection at the submerged reef, seem to be slightly inconsistent with literature, such as in (Young and Testik, 2011)) where monochromatic waves were used to approximate reflection coefficients and had a good fit with measured data. The same approximation shows that reflection is mainly reliant on incident wave and reef height. When used on this studies scenario, reef reflection is predicted around $10 \%$ for reef 1 and reef 2 , much larger than that modeled by FUNWAVE. One factor for this difference is likely the highly nonlinear waves used in these FUNWAVE simulations. This causes waves to act differently, such as having a majority of their energy and height translated into the wave crest, especially in the nearshore region, allowing for more of the wave to pass over the reef. 
Wave reflection is an important consideration in any coastal modeling around solid objects such as sea walls or steep beach faces and could play a larger role in the future modeling of different reef shapes and locations.
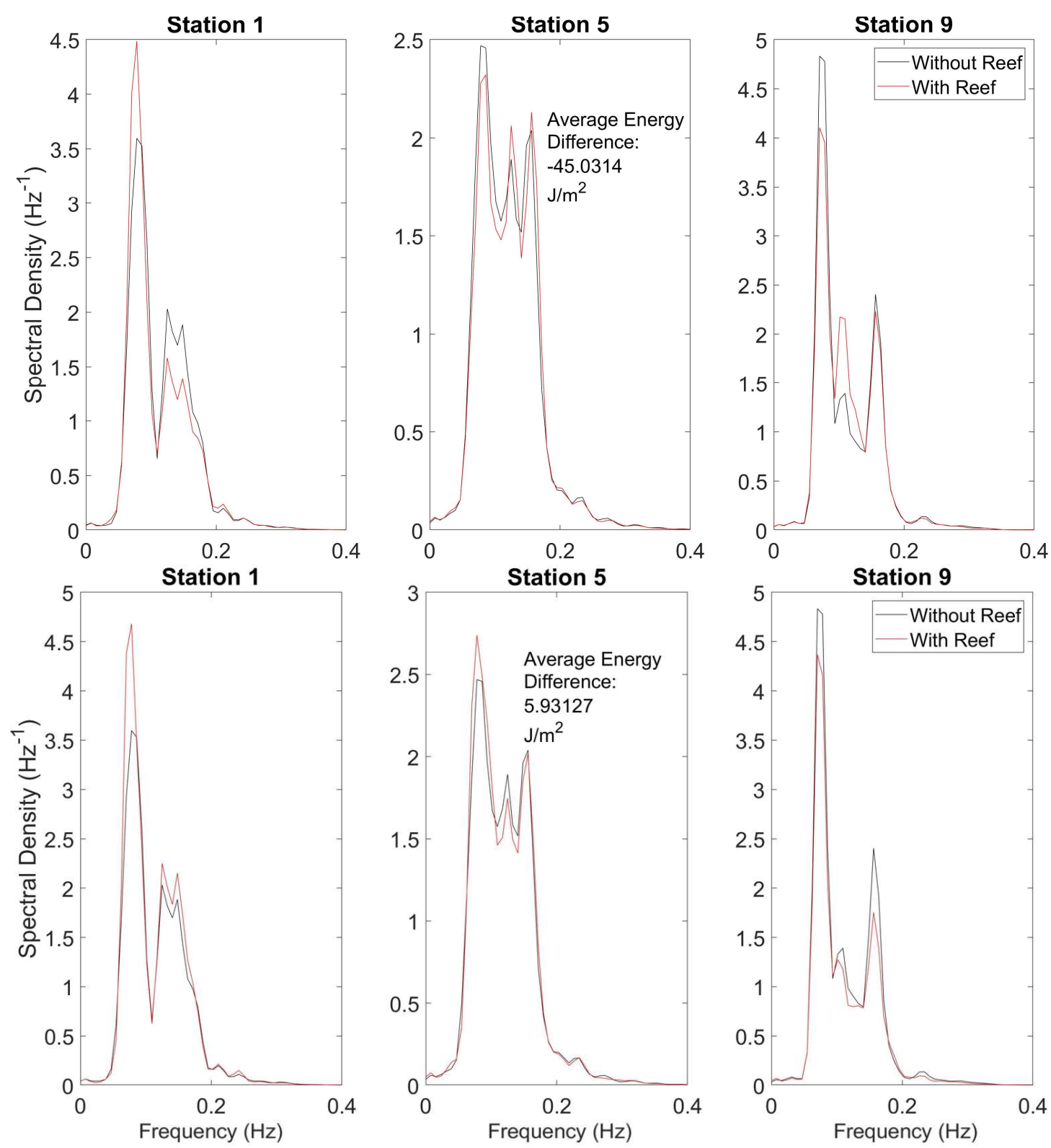

Figure 19: Power Spectrum Density for Reef 1 (top) and Reef 2 (bottom) 200m offshore of the reef. The difference between the integral of the spectrum with and without a reef is representative of reflected energy. 


\subsection{Sediment Transport Comparison}

To best understand the erosion and accretion calculated by the FUNWAVE sediment transport module, a comparison was made to the calibrated and verified XBeach model, using simulations run over the same study area with an identical wave climate and duration.

The resulting sediment erosion per meter of beach between MSL (NAVD88) and the dune crest at a transect in the center of the study area can be found in Table 6. Table 7 shows the resulting sediment change along the same transect, extending 2 meters below MSL to show sediment changes in the close nearshore region. These values are calculated from summing the erosion/ accretion volume along the transect line at the last time step in the simulation. Across the shoreline, sediment change is displayed in cubic meters, shown in Figure 20.

Table 6: Sediment change along transect directly inshore of the reef location in the study area. Values calculated between MSL (NAVD88) and the dune crest.

\begin{tabular}{|c|c|c|}
\hline Simulation & FUNWAVE & XBeach \\
\hline No Reef (1h) & $-0.174 \mathrm{~m}^{3}$ per $\mathrm{m}$ (erosion) & $-0.127 \mathrm{~m}^{3}$ per $\mathrm{m}$ (erosion) \\
\hline Reef 1 (1h) & $-0.108 \mathrm{~m}^{3}$ per $\mathrm{m}$ (erosion) & $-0.037 \mathrm{~m}^{3}$ per $\mathrm{m}$ (erosion) \\
\hline
\end{tabular}

Table 7: Sediment change along transect directly inshore of the reef location in the study area. Values calculated between 2 meters below MSL and the dune crest.

\begin{tabular}{|c|c|c|}
\hline Simulation & FUNWAVE & XBeach \\
\hline No Reef (1h) & $1.134 \mathrm{~m}^{3}$ per $\mathrm{m}$ (accretion) & $0.018 \mathrm{~m}^{3}$ per $\mathrm{m}$ (erosion) \\
\hline Reef 1 (1h) & $4.135 \mathrm{~m}^{3}$ per $\mathrm{m}$ (accretion) & $0.051 \mathrm{~m}^{3}$ per $\mathrm{m}$ (erosion) \\
\hline
\end{tabular}




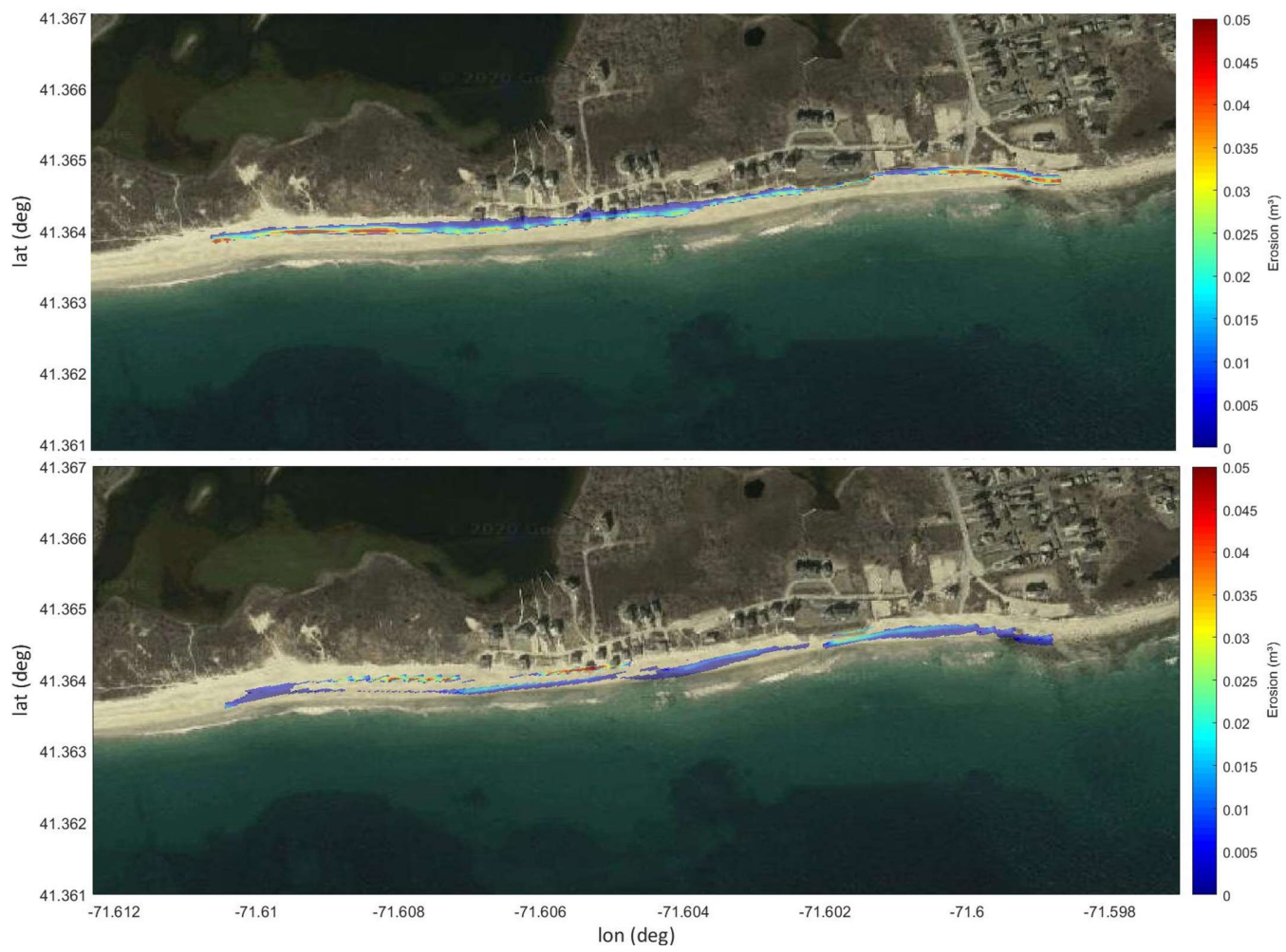

Figure 20: Erosion above MSL (NAVD88) in $\mathrm{m}^{3}$ after one hour of waves, FUNWAVE no reef (a), XBeach no reef (b)

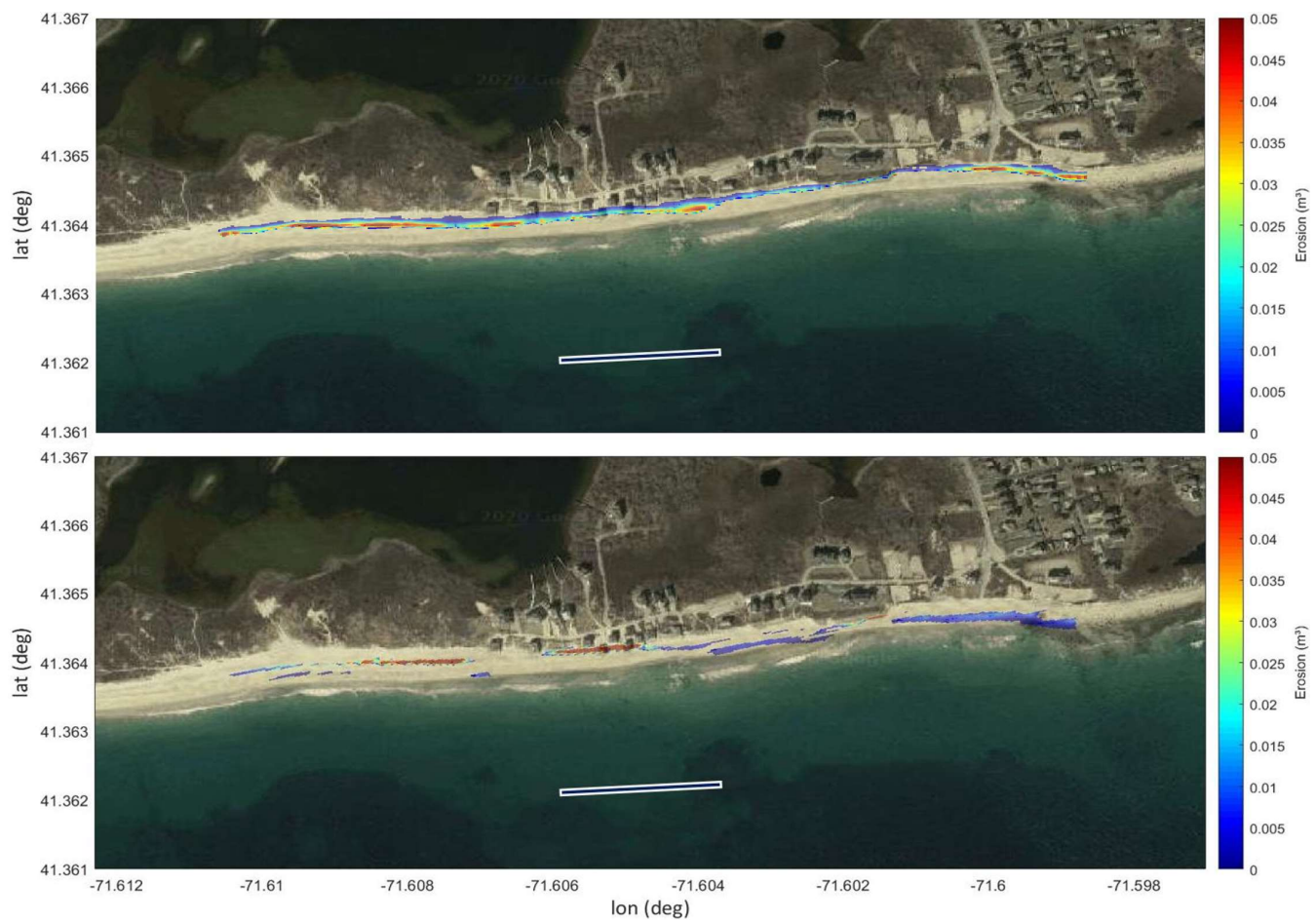

Figure 21: Erosion above MSL (NAVD88) in $\mathrm{m}^{3}$ after one hour of storm waves, FUNWAVE reefl (a), XBeach reefl (b) 
When comparing the 1-hour simulations, XBeach and FUNWAVE predict subaerial sediment changes in acceptable agreement (27\% less erosion with XBeach), without a reef (above MSL; NAVD88), but very different values when the reef is added (less erosion in both cases, but $79 \%$ less erosion estimated with XBeach than in FUNWAVE). In addition, predicted accretion and erosion below MSL strongly varies with both models.

It's important to recall that the physical processes included in XBeach are limited. Xbeach does not model waves in the time domain and does not include either reflection or diffraction, limiting its relevance and accuracy when deploying an offshore structure. In addition, simulating an extreme storm event for such a short period presents significant challenges for a comparison. While the XBeach parametrization is valid for the entire storm length, its validity is not demonstrated when reproducing isolated time segments of the storm. The fundamental differences between the models adds an epistemic uncertainty that is difficult to isolate when using such a short time segment from an event. Results will still be briefly discussed in the following pages, keeping the above limitations in mind.

After Hurricane Irene, direct measurements on transects across the beach show a sub-aerial erosion on the order of 15 to $30 \mathrm{~m}^{3}$ per meter of cross-shore beach length (Schambach et al., 2018). Over the 48 hours storm, XBeach simulations accurately reproduced these values on the order of $6 \%$. While the erosion observed during the current short simulation durations is not linearly representative of the erosion occurring during the full storm (no tides, or longer term sediment processes), a quick linear estimation would provide an erosion estimate of 2-3 orders of magnitude smaller than 
observed during the full storm. Presuming that the short time is an acceptable tool to investigate the differences between the models, the relative acceptable agreement without a reef present leased us to believe we can also trust the differences when a reef is present. It's important to note FUNWAVE's expensive computational runtime, especially with the sediment transport module addition, combined with the need for a long grid to capture long-waves, excluded runtimes longer than the 1-hour simulation for the purpose of the current study.

Looking solely at the FUNWAVE sediment transport results (Figure 22) some simple initial conclusions can be drawn. First, the addition of the reef induces strong erosion on the shoreward side of the reef toe. Second, although the reef creates slightly more erosion above MSL over the hour duration, it reduces erosion and promotes accretion just below MSL. This build up is backed by the values shown in Table 7 and could further protect the shoreline as the storm continues for more than an hour. 

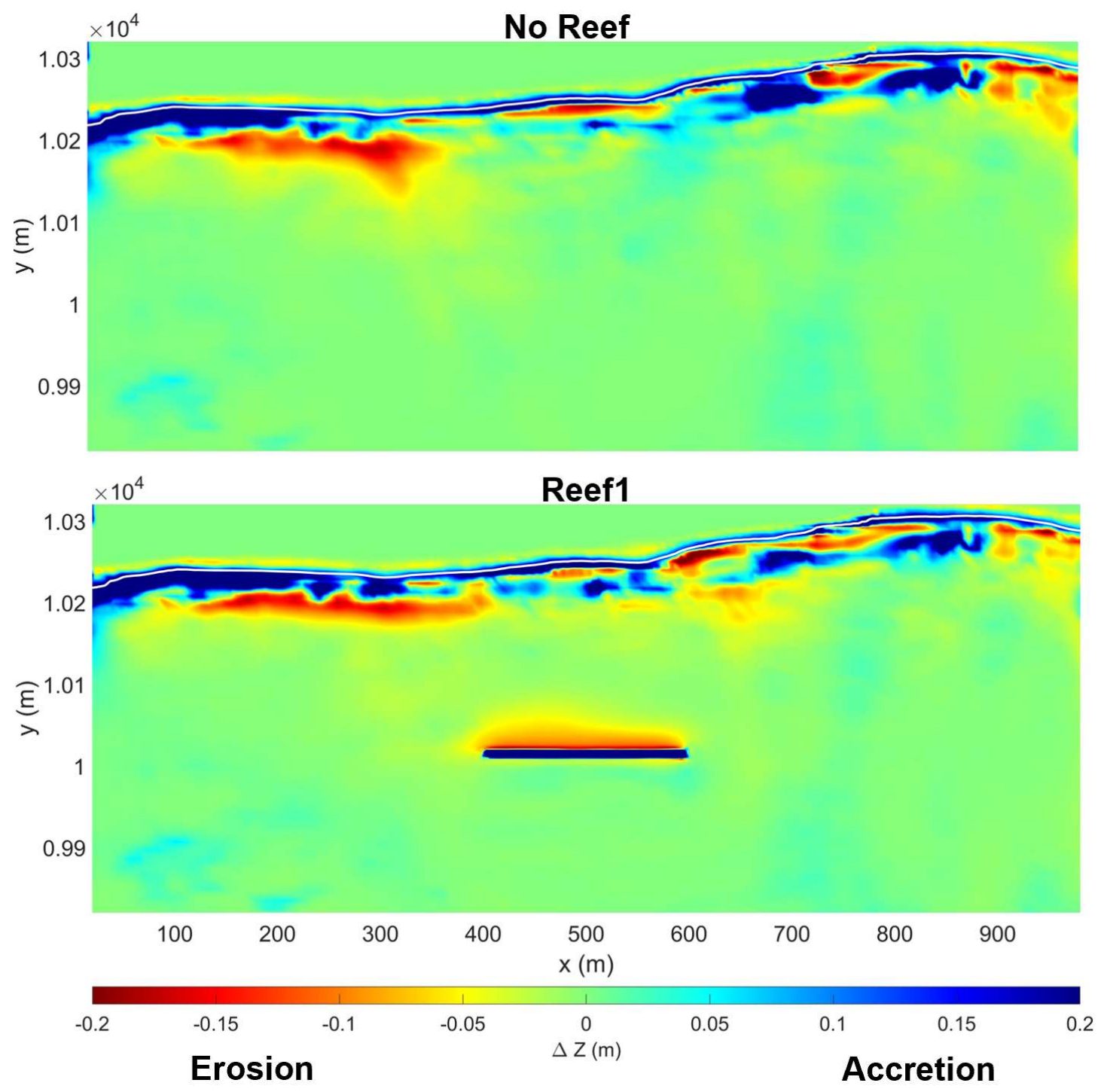

Figure 22: Nearshore erosion simulated using FUNWAVE after one hour of modeled time. No reef case (Top). Reef 1 case (Bottom). 


\section{Conclusion}

FUNWAVE is a powerful wave and coastal processes simulation tool. Long simulation runtimes lead us to believe that time-sensitive research might be more feasible utilizing other modeling tools. However, given a sufficient amount of time/ processing power this tool is able to produce extremely accurate and consistent nearshore wave modeling.

The value of the transmission coefficient, significantly departing from earlier studies (Grilli et al., 1994), provides an insight into the epistemic uncertainty associated with the choice of the model and the physics included in the model, during a hazard impact assessment. Despite FUNWAVE's perceived accuracy, this study needs to be compared to empirical measurements to assess the error associated with the numerical simulations.

From the resulting current velocities, it is evident that when a reef is deployed in this study area, highly focused wave induced currents are produced over the reef area with a much larger and calmer region shoreward of the reef. This is likely due to wave reflection, breaking and friction at the reef. Further current research in this area needs to be completed with a higher sampling frequency in the grid surrounding the reef. The case of a lone reef also reduces the chances of rip currents forming in reef gaps, typically seen between reef segments during a more realistic installation.

Looking at the frequency spectrums offshore of the reef locations, there seems to be no reflection induced by the deployment of the two reef examples in the model. This is likely due to the highly irregular waves transporting energy mostly above the MSL 
and transmitting across the reef without reflecting. Reflection should be further studied for similar reef cases as theoretically it can play a small but significant role in energy reduction shoreward.

Although we have conclusively shown a reduction in wave energy and current velocities shoreward of the reef, when compared to the no reef case, sediment erosion along the shoreline does not completely reflect the other findings or identical simulations run in XBeach. The erosion above MSL is not reduced with the deployment of the reefs. While FUNWAVE is extremely capable and verified in wave and fluid mechanics, an initial look at FUNWAVE's sediment module, when compared to the validated XBeach model, shows it seeming to be working correctly coupled with the parameters used in this study. However, this initial work cannot be taken as a window into how the model would behave for the full storm. One reason for this is the short duration the waves spend interacting with the shoreline during this study's simulations (less than 1 hour). Further research, containing longer simulation times and more transect comparisons is needed to better evaluate FUNWAVE's sediment transport module. For the sake of this study, it is best to trust FUNWAVE's more widely validated irregular wave and current effects around the submerged reefs. 


\section{BIBLIOGRAPHY}

Beach SAMP, 2020. RI Shoreline Change Special Area Management Plan. https://www.beachsamp.org/. Accessed 12 May 2020.

Beck, M.W., Losada, I.J., Menéndez, P., Reguero, B.G., Díaz-Simal, P., Fernández, F., 2018. The global flood protection savings provided by coral reefs. Nature communications 9 (1), 2186. doi:10.1038/s41467-018-04568-z.

ELGAR, S., HERBERS, T.H.C., OKIHIRO, M., OLTMANSHAY, J., GUZA, R.T., 1993. OBSERVATIONS OF INFRAGRAVITY WAVES (JOURNAL OF GEOPHYSICAL RESEARCH, VOL 97, PG 573, 1992). AMER GEOPHYSICAL UNION 2000 FLORIDA AVE NW, WASHINGTON, DC 20009 98, 991-991.

Forristall, G.Z., 1978. On the statistical distribution of wave heights in a storm. J. Geophys. Res. 83 (C5), 2353-2358.

Grilli, A., Spaulding, M.L., Oakley, B.A., Damon, C., 2017a. Mapping the coastal risk for the next century, including sea level rise and changes in the coastline: application to Charlestown RI, USA. Nat Hazards 88 (1), 389-414. doi:10.1007/s11069-017-2871-x.

Grilli, A.R., Spauding, M.L., Schambach, L., Smith, J., Bryant, M., 2017b. Comparing Inundation Maps Developed Using WHAFIS and STWAVE: A Case Study in Washington County, RI, in: , Coastal Structures and Solutions to Coastal Disasters 2015: Resilient Coastal Communities. American Society of Civil Engineers Reston, VA, pp. 147-160. 
Grilli, A.R., Westcott, G., Grilli, S.T., Spaulding, M.L., Shi, F., Kirby, J.T., 2020.

Assessing coastal hazard from extreme storms with a phase resolving wave model:

Case study of Narragansett, RI, USA. Coastal Engineering, 103735.

Grilli, S.T., Losada, M.A., Martin, F., 1994. Characteristics of solitary wave breaking induced by breakwaters. J. Waterway, Port, Coastal, Ocean Eng. 120 (1), 74-92.

Harborne, A.R., Mumby, P.J., Micheli, F., Perry, C.T., Dahlgren, C.P., Holmes, K.E., Brumbaugh, D.R., 2006. The functional value of Caribbean coral reef, seagrass and mangrove habitats to ecosystem processes. Advances in marine biology 50, $57-189$.

Kennedy, A.B., Zhang, Y., Haas Kevin A., 1Dept. of Civil and Coastal Engineering, Univ. of Florida, Gainesville, FL 32611-6590. 2Dept. of Civil and Coastal Engineering, Univ. of Florida, Gainesville, FL 32611-6590. 3Dept. of Civil and Environmental Engineering, Georgia Institute of Technology, 210 Technology Circle, Savannah, GA 31407., 2008. Rip Currents with Varying Gap Widths.

Kirby, J., Grilli, S.T., Shi, F., Tehranirad, B., Park, Y.S., Shelby, M. (Eds.), 2015. FUNWAVE-TVD Benchmark Results. Tsunami Current Modeling Workshop, $136 \mathrm{pp}$.

Longuet-Higgins, Michael S., and R. W. Stewart, 1964. Radiation stresses in water waves; a physical discussion, with applications Vol. 11. No. 4.

Lynett, P., Liu, P.L.-F., 2005. A numerical study of the run-up generated by threedimensional landslides. J. Geophys. Res. 110 (C3). doi:10.1029/2004JC002443. Meyer-Peter, E., Müller, R. (Eds.), 1948. Formulas for bed-load transport. IAHR. 
Naser, A., Grilli, A., Grilli, S., Baxter, C., Bradshaw, A., Maggi, B., 2018. Land use and mitigation effects on barrier beach erosion in storms: Case study in Rhode Island. Coastal Engineering Proceedings (36), 108.

NOAA, 2020. Station Home Page - NOAA Tides \& Currents. https://tidesandcurrents.noaa.gov/stationhome.html?id=8452660. Accessed 10 June 2020.

Park, H., Do, T., Tomiczek, T., Cox, D.T., van de Lindt, J.W., 2018. NUMERICAL MODELING OF NON-BREAKING, IMPULSIVE BREAKING, AND BROKEN WAVE INTERACTION WITH ELEVATED COASTAL STRUCTURES. Coastal Engineering Proceedings (36), 31.

Reguero, B.G., Beck, M.W., Agostini, V.N., Kramer, P., Hancock, B., 2018. Coral reefs for coastal protection: A new methodological approach and engineering case study in Grenada. Journal of environmental management 210, 146-161. doi:10.1016/j.jenvman.2018.01.024.

Roelvink, D., Reniers, A., van Dongeren, A.P., van Vries, J.T. de, McCall, R., Lescinski, J., 2009. Modelling storm impacts on beaches, dunes and barrier islands. Coastal Engineering 56 (11-12), 1133-1152.

Schambach, L., Grilli, A.R., Grilli, S.T., Hashemi, M.R., King, J.W., 2018. Assessing the impact of extreme storms on barrier beaches along the Atlantic coastline: Application to the southern Rhode Island coast. Coastal Engineering 133, 26-42. doi:10.1016/j.coastaleng.2017.12.004. 
Shi, F., Kirby, J.T., Harris, J.C., Geiman, J.D., Grilli, S.T., 2012. A high-order adaptive time-stepping TVD solver for Boussinesq modeling of breaking waves and coastal inundation. Ocean Modelling 43, 36-51.

Spaulding, M., Grilli, A., Damon, C., Fugate, G., Oakley, B., Isaji, T., Schambach, L., 2017. Application of State of Art Modeling Techniques to Predict Flooding and Waves for an Exposed Coastal Area. JMSE 5 (1), 10. doi:10.3390/jmse5010010. Spaulding, M.L., Grilli, A., Damon, C., Crean, T., Fugate, G., Oakley, B.A., Stempel, P., 2016. STORMTOOLS: coastal environmental risk index (CERI). JMSE 4 (3), 54.

Stockdon, H.F., Sallenger Jr, A.H., Holman, R.A., Howd, P.A., 2007. A simple model for the spatially-variable coastal response to hurricanes. Marine Geology 238 (1-4), $1-20$.

Torres, M.J., Reza Hashemi, M., Hayward, S., Spaulding, M., Ginis, I., Grilli, S.T., 2019. Role of Hurricane Wind Models in Accurate Simulation of Storm Surge and Waves. J. Waterway, Port, Coastal, Ocean Eng. 145 (1), 4018039. doi:10.1061/(ASCE)WW.1943-5460.0000496.

van Dongeren, A.P., Lowe, R., Pomeroy, A., Trang, D.M., Roelvink, D., Symonds, G., Ranasinghe, R., 2013. Numerical modeling of low-frequency wave dynamics over a fringing coral reef. Coastal Engineering 73, 178-190.

van Rijn, L.C., 1984. Sediment pick-up functions. Journal of Hydraulic engineering $110(10), 1494-1502$.

Young, D.M., Testik, F.Y., 2011. Wave reflection by submerged vertical and semicircular breakwaters. Ocean Engineering 38 (10), 1269-1276. 